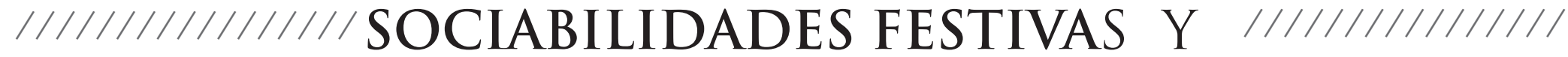 CONSTRUCCIÓN DE ESPACIO PÚBLICO A TRAVÉS DE LAS AUDICIONES SALSERAS EN SANTIAGO DE CALI
}

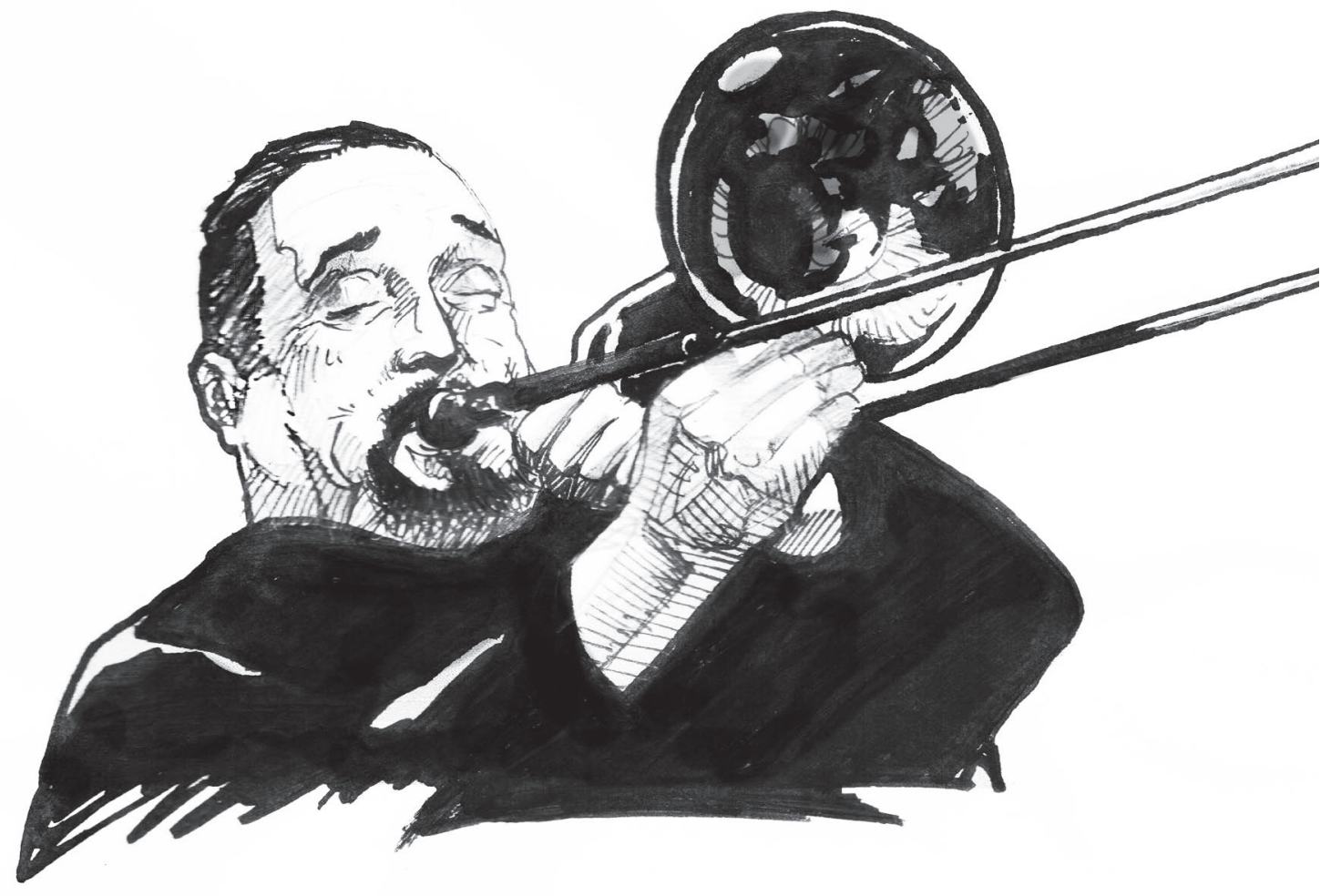

Por:

\section{Alejandro Ulloa Sanmiguel}

Profesor Titular Escuela de Comunicación Social Universidad del Valle

alejandro.ulloa@correounivalle.edu.co

"La música es "cosa corporal». Encanta, arrebata, mueve y conmueve: está menos más allá de las palabras que más acá, en los gestos y movimientos del cuerpo, en los ritmos, en los arrebatos y los apaciguamientos, en las tensiones y las calmas. La más "mística», la más "espiritual» de las artes quizá sea simplemente la más corporal. Sin duda, es esto lo que hace tan difícil hablar de música de otra manera que no sea mediante adjetivos o exclamaciones" Pierre Bourdieu ("El origen y la evolución de las especies de melómanos") 


\section{$/ / / / / / / / /$ FESTIVE SOCIABILITY AND CONSTRUCTION OF PUBLIC SPACE THROUGH THE SALSA AUDITIONS ON SANTIAGO DE CALI}

Resumen: El artículo presenta los resultados de una investigación etnográfica sobre las audiciones de música salsa como prácticas de recepción y consumo musical en espacios públicos de la ciudad. Se discute la noción de espacio público, se relata el origen y desarrollo de estas prácticas en función del coleccionismo discográfico, sus causas y los modos como se construyen sociabilidades en una relación particular con el espacio urbano. A partir de una tipología de las audiciones se diferencian aquellas que tienen un respaldo institucional, de las que se realizan por colectivos de melómanos mediante formas de organización y gestión autónomas, sin mayor apoyo oficial. Se contrastan los dos "modelos" y se analizan las connotaciones políticas de sus discursos y representaciones de lo público. Los resultados de la investigación propician, de principio a fin, un debate con el texto del sociólogo Pierre Bourdieu sobre "Las distintas especies de melómanos", en el que se alude a los conciertos en vivo de música culta, la relación de los melómanos con la discografía y la formación de gustos y culturas musicales en la sociedad moderna.

Palabras Clave: Audiciones Musicales, Sociabilidades, Melómanos, Coleccionistas, Producción del Espacio, Espacio Público.

Resumen: The article presents the results of an ethnographic investigation about salsa music auditions as practices of musical reception and consumption on public's spaces of the city. The notion of public space is discussed, the origin and development of these practices in terms of record collecting is related, its causes and the ways sociability are constructed in a particular relationship with the urban space. From a typology of auditions: those with institutional support to those make it by collective of music lovers through autonomous forms of organization and management, without much official support. The two "models" are contrasted and political connotations of his speeches and performances of the public are analyzed. The research results are conducive, from beginning to end, a debate with the text of the sociologist Pierre Bourdieu on "The different species of music lovers", in which alludes to the live concerts of classical music, the relationship of music lovers with discography and formation of musical tastes and cultures in modern society.

Keywords: Musical Auditions, Sociability, Music Lovers, Collectors, Production of Space, Public Space. 


\section{Introducción}

El propósito de este artículo gira en torno a las sociabilidades que se construyen o se fortalecen mediante ciertas prácticas de recepción y consumo de la música salsa que tienen lugar en calles, plazas y parques de Santiago de Cali, principalmente en algunos de sus barrios populares. Tales prácticas, mediatizadas por las tecnologías del sonido y el disco en acetato o en vinilo, configuran una puesta en escena en la que se proyectan afectos, sensibilidades, actitudes y conocimientos, al lado de discursos sociales y valores culturales agenciados por los actores que organizan y realizan las audiciones salseras. De ese modo dan lugar a otras formas de habitar la ciudad, al marcar territorios donde se afirman afinidades identitarias con sus apoyos, alianzas y solidaridades.

Por otro lado, a partir del análisis que sigue se discutirán algunos puntos de vista expuestos por Pierre Bourdieu sobre el consumo musical. ${ }^{1}$ Pero en nuestro caso no se trata de las audiciones de música en vivo, ni de los conciertos de música culta al aire libre, y ni siquiera de los conciertos de salsa en espacio abierto, como es de suponer. Se trata de las audiciones discográficas, un fenómeno que, virtualmente, tendría que haber desaparecido, pero subsiste con fuerza en pleno siglo XXI desafiando el imperio de las nuevas tecnologías en la ciudad. En su exposición, Bourdieu no alude a las audiciones públicas de música popular como las que analizaremos en este artículo y que nos llevan a consideraciones distintas. Por el contrario, aunque plantea cómo las diferencias de clase se manifiestan en las diferencias de los gustos musicales, sus referencias se centran en las prácticas de las élites burguesas. Al respecto dice:

Basta con tener presente que no hay práctica más enclasante [classante], más distintiva, es decir, más estrechamente ligada a la clase social y al capital escolar poseído, que la asistencia asidua a conciertos o la práctica de un instrumento de música «noble» (... ) para comprender que el concierto estaba predispuesto a convertirse en una de las grandes celebraciones burguesas. (Bourdieu, 2000, p. 140).

Podemos decir, siguiendo a Bourdieu, que las audiciones mediatizadas por la discografía también están asociadas en Cali a un capital cultural y un "enclasamiento", pero de los sectores subalternos, es decir trabajadores independientes, estudiantes, obreros y empleados, o incluso jóvenes profesionales, como se deduce de las actividades desempeñadas por quienes organizan, dirigen y asisten a las audiciones.

Según Bourdieu (2000):

la exaltación de los artistas del pasado de la que dan fe las innumerables reediciones de antiguas grabaciones a 78 revoluciones o de grabaciones radiofónicas- sin duda guarda relación con la aparición de una cultura musical basada en el disco, más que en la práctica de un instrumento y en la asistencia asidua a conciertos; y en la banalización de la perfección instrumental que imponen la industria del disco y la competencia inseparablemente económica y cultural entre los artistas y los productores. (p. 142) 
De cualquier manera, la emergencia de las audiciones como una práctica social son efectivamente la expresión de "una cultura musical basada en el disco", que resulta de la relación compleja entre la industria discográfica transnacional, el mercado del entretenimiento, la radio y sectores sociales urbanos de extracción popular y obrera que con el tiempo han acumulado un patrimonio dotado de un alto valor simbólico para sus propietarios. En esta ecuación, nuestra modernidad tardía puso en contacto a los cuatro actores en juego, ejerciendo roles desiguales pero complementarios que originaron el fenómeno.

Ahora bien, independientemente de la banalización instrumental, lo que la indagación etnográfica nos muestra es la riqueza en intercambios, significaciones, simbolismos y connotaciones políticas que generan las audiciones discográficas como prácticas de recepción y consumo musical en las que el uso no se reduce a una actitud contemplativa y diletante de los bienes culturales apropiados por los sectores sociales agentes del fenómeno. En contraste, se trata de un activismo y una dinámica consolidados en la ciudad, que merecen ser tenidos en cuenta para una reflexión sobre los usos de la misma.

Como un nuevo producto de mi investigación sobre La Salsa en Cali este artículo es resultado de la indagación sistemática realizada a lo largo de varios años en distintos momentos y en contacto permanente con los actores que agencian las audiciones salseras, participando de ellas, registrándolas fotográficamente y en video, recogiendo testimonios de diversos tipos de asistentes, entrevistando a los organizadores e interviniendo en las audiciones como un melómano más que lleva sus discos y los presenta ante el público.

Por eso, antes que referencias bibliográficas previas sobre las audiciones de salsa, que probablemente existan, este análisis es producto de la observación participante y la participación observante del autor, mediada por una conceptualización crítica que lo sustenta. ${ }^{2}$

Pero, además de registrar empíricamente los acontecimientos y contextualizarlos, se propone una interpretación que los trasciende, a partir de una reflexión sobre la producción social del espacio, las relaciones de los actores con el espacio público y las implicaciones socioculturales que tienen dichas audiciones como prácticas de recepción y consumo musical, pero también como prácticas significantes, es decir, productoras de sentidos profundos ligados al placer y el disfrute de la ciudad, al baile, al erotismo y a la creación de nuevos lazos sociales, o al fortalecimiento de los que ya existen, gracias a esta música.

Algunas de las preguntas que orientaron la indagación son las siguientes: ¿Quiénes son los actores que promueven y dirigen las audiciones de música salsa en la ciudad? ¿Cómo son sus formas de organización y gestión? ¿Cuál es su capacidad de convocatoria y a través de qué medios lo hacen? ¿Cómo se construye una relación con el espacio público urbano? ¿Mediante qué prácticas sociales consolidan esa relación? ¿Hay algún tipo de connotaciones políticas en las audiciones salseras? Si las hay, ¿Qué diferencias existen entre estas formas de apropiación y ocupación del espacio con otras experiencias como la protesta que se asume de manera explícita por organizaciones sociales y políticas? 


\section{Las Sociabilidades}

Para la sociología, el concepto de Sociabilidad se entiende como el proceso de producción de los vínculos sociales en la vida cotidiana, en sus multiples manifestaciones públicas y privadas. La sociabilidad es fundamental para la construcción del sujeto y la subjetividad, para generar formas de identificación entre las personas, o de ellas con algún fenómeno social o cultural.

En otro sentido, la sociabilidad puede considerarse como la orientación intuitiva del sujeto para establecer relaciones con los demás, compaginar intereses u objetivos comunes, desarrollar formas de interacción, crear espacios de cooperación e intercambio y configurar vínculos colectivos. Ahora bien, los procesos de sociabilidad se inscriben en contextos histórico-sociales determinados, de los que surgen y de los que hacen parte con una dinámica propia pero con diferentes ramificaciones en la vida cotidiana.

Destacaré un tipo de sociabilidades construido en torno a la música salsa, específicamente alrededor de dos prácticas ya habituales en la ciudad, sobre todo entre las comunidades de melómanos salseros. Son ellas el baile y las audiciones. Se trata de dos prácticas que devienen en formas de apropiación de esta música que, aunque no es originaria de la ciudad ha sido adoptada como si lo fuera. Dos prácticas de recepción y consumo musical que se relacionan y constituyen manifestaciones explícitas - o indicadores - de una cultura salsera en Santiago de Cali.

Un análisis diacrónico de ellas nos revela sus continuidades y transformaciones durante la segunda mitad del siglo XX, hasta hoy. Y la observación detallada de su dinámica interna, mediante la descripción etnográfica, nos revela su discursividad y formas de representación, sus procedimientos organizativos, los estatutos de prestigio en cada una de ellas y las tensiones propias de esa cultura en el contexto urbano contemporáneo.

Aunque aludiré eventualmente al baile como una forma de ritualizar las relaciones sociales, el objetivo de este artículo es analizar el fenómeno de las audiciones públicas y privadas, sobre todo las primeras, por su especial relación con el espacio público, la calle y el barrio popular caleño.

\section{El espacio público y la "producción del espacio social"}

Pero antes de describir las audiciones expondré lo que entiendo por "espacio público", como una noción diferente a la que predomina en el sentido común, en los medios de comunicación y en ciertos discursos oficiales. Aunque el concepto de espacio público se ha utilizado por muchos autores con diferentes acepciones, en Colombia "sólo aparece consolidado institucionalmente a partir de la constitución de 1991 que reconoce de manera explícita el derecho al uso del espacio público" (Botero, 2004, p. 9) 3 . 
Para efectos de este artículo defino el espacio público no como los andenes, las calles y las plazas invadidas por los vendedores ambulantes (según el concepto predominante en el discurso oficial y mediático) sino como la esfera de confrontación y negociación de intereses por distintos actores, o por distintos sectores ciudadanos que le dan significado al espacio, mediante la reivindicación, la movilización y la lucha, al defender objetivos comunes, o mediante el encuentro lúdico y socializador, donde también se construyen los vínculos, los arraigos y los sentidos de pertenencia.

En este orden de ideas, el espacio público no es un espacio público a priori, definido institucionalmente, sino un espacio construido a partir de los usos que los ciudadanos hacen de él y de las prácticas que efectúan en él, dotándolo de significaciones que pueden variar en el tiempo, según las dinámicas sociales que determinan los usos y las prácticas en su intensidad y sus calidades.

Por otro lado, el espacio público, tal como se define aquí, no es sólo un lugar físico en la geografía de la ciudad, sino un espacio simbólico ensamblado en la memoria y convertido en relato por medio del lenguaje verbal o mediante otros sistemas de representación. En el caso que nos ocupa, las prácticas y los usos por medio de los cuales se construye el espacio público que describiremos más adelante en función de las audiciones, están determinados por la existencia de unas propuestas gestadas colectivamente por grupos específicos que agencian un discurso, un decir y un hacer, en torno a la música salsa en Santiago de Cali.

Desde otraperspectiva, las formas de apropiación y construcción del espacio a través de las audiciones públicas corresponden a lo que Henry Lefebvre llama "las prácticas espaciales", "en la producción del espacio social". Es decir, aquellas en las que el espacio es percibido, recorrido y ocupado vitalmente en calles, plazas, parques, como un lugar sentido y practicado. Una práctica espacial donde "la fiesta colectiva y la revuelta son parientes cercanas”, según la expresión del español Manuel Delgado. Esta producción del espacio es distinta en Lefebvre de las representaciones del espacio que corresponden al ejercicio del poder, la ideología y el control en la planeación por parte de urbanistas, tecnócratas y planificadores que establecen usos funcionales, incluyendo restricciones y reglas de control que hacen del

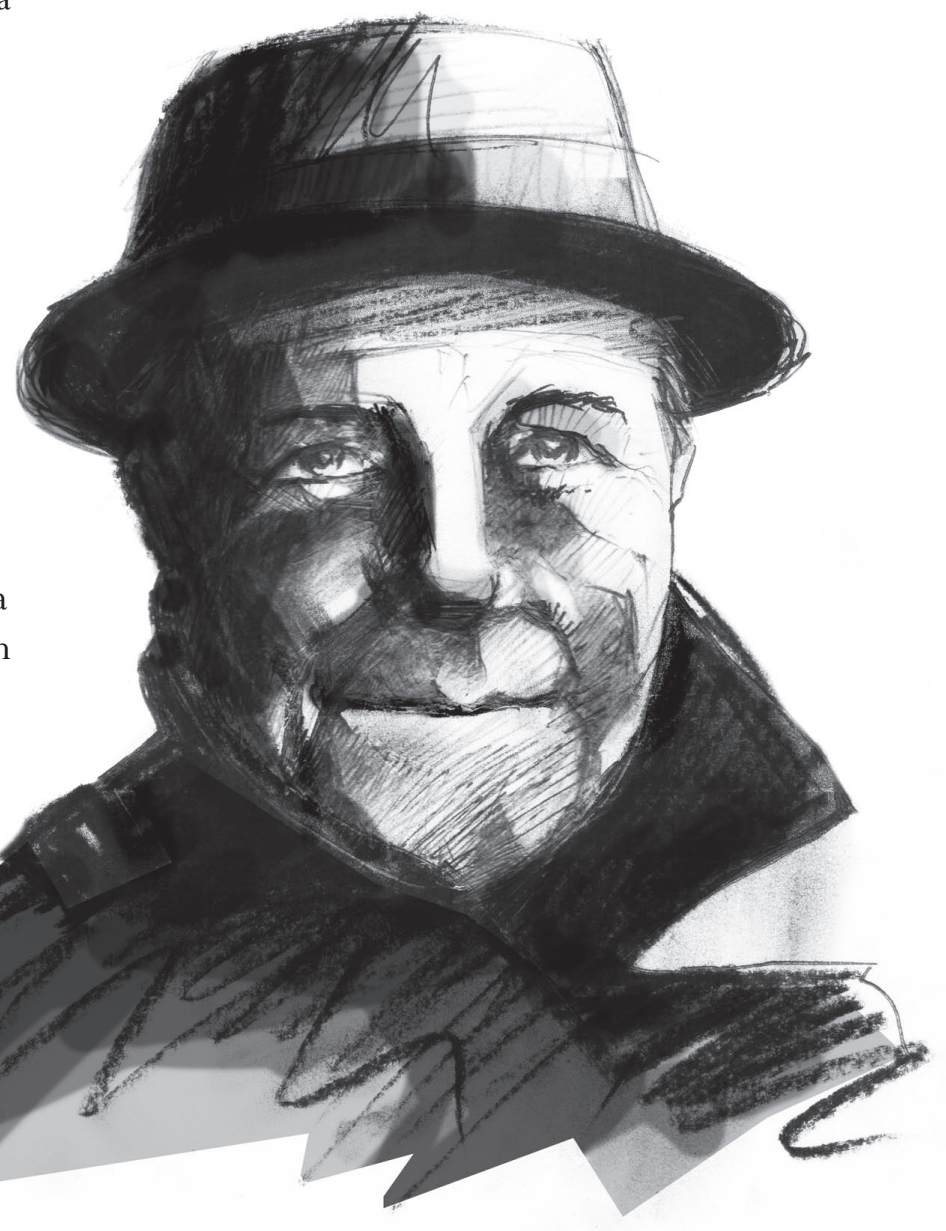


espacio un lugar para el conflicto. Y distinta también de los espacios de representación, o sea el de los artistas que perciben y recrean el espacio a través de una mirada propia mediante la ensoñación y la fantasía creadora del arte.

\section{Las audiciones salseras: una mediación tecnológica y cultural}

En una primera aproximación se puede decir que las audiciones de salsa y música latina (incluida la "vieja guardia antillana", de Cuba y Puerto Rico) son reuniones organizadas para escuchar y confraternizar en torno a ellas, disfrutarla colectivamente, explorarla en sus contenidos, compartirla entre los participantes y narrar su relación con ella. Su origen, en los años 70 del siglo pasado, como forma de consumo y práctica de recepción en Santiago de Cali está asociada directamente con la existencia de un patrimonio discográfico que reposa en manos de melómanos y coleccionistas que durante décadas se han dedicado a comprar los discos y preservarlos como un pequeño tesoro privado que con el tiempo se ha hecho público.

En las audiciones lo que se celebra es la salsa y el encuentro en torno a ella. Ella es el vínculo que propicia el acontecimiento de la audición, como un evento comunicativo rico en intercambios y significaciones. Como prácticas de recepción y consumo colectivo, las audiciones se producen tanto en el ámbito privado, como en el espacio público. Entre las audiciones privadas podemos identificar dos clases: las que transcurren en casas de familia o en apartamentos, y las que acontecen en bares, tabernas y salsotecas, las cuales configuran un lugar intermedio entre las audiciones privadas, y las audiciones públicas en calles, parques y plazas de los barrios. En adelante nos ocuparemos tan sólo de las privadas y luego de las audiciones públicas.

Las primeras consisten en el encuentro que surge de un modo más o menos espontáneo, que termina volviéndose una cita más o menos programada con la salsa para disfrutarla, apreciarla en sus distintas dimensiones, cantarla, comentarla, interpretarla con algún instrumento a la mano, incluso el cuerpo y hasta bailarla, si se desea.

A la audición privada sólo asisten los amigos más cercanos, grupos pequeños de salseros entusiastas que se reúnen para conocer más acerca de la música que los identifica; concurren interesados en profundizar en la vida y la obra de un artista, una orquesta, un compositor, un género en particular, una época, o en todas las anteriores. En el ejercicio de esta práctica privada iniciada en algunas casas de familia, identificamos desde la audición programada con un objetivo y un libreto previo, hasta la audición espontánea fraguada con los gustos personales del discómano de turno que marca la pauta o reta a sus compañeros como en un juego con sentido agonístico.

En cualquier caso, es una experiencia propia surgida en los sectores populares, una vivencia del Barrio que, durante la década del 90 trascendió a sectores de clase media donde también se cultiva, aunque en menor escala. Es preciso enfatizar en otra condición indispensable - ya mencionada - que hace posible la audición pública o privada. Se trata de la música, pero no de la música en vivo, sino de la música mediatizada por una tecnología del sonido, a saber, el disco en acetato o en vinilo, primordialmente, que convive junto al $\mathrm{CD}$, si es original. 


\section{El coleccionismo discográfico}

\section{Melómanos en su salsa: del coleccionismo a las audiciones}

Como práctica social de los melómanos, las audiciones existían en esta ciudad desde mucho antes que se formalizaran públicamente. Más allá del valor comercial, hay en el coleccionismo salsero un profundo deseo invertido en cada disco; una íntima relación con el pasado de esta música y con la historia de cada melómano por donde transita la memoria individual y colectiva de varias generaciones en Santiago de Cali. En sus discos está también su vida. Recuerdos, afectos y emociones, instantes gozados y sufridos, placeres secretos o amores bailados que se encierran en la dura pasta del acetato y en el diseño audaz de una carátula. Allí reposan firmas y dedicatorias, huellas escritas como marcas sobre la superficie de un territorio poseído, íntimo y a la vez compartido con quienes experimentan el mismo placer de una historia, o un instante común en la ciudad. Por eso las audiciones al aire libre son una ofrenda a la memoria de la salsa y a la historia colectiva de los salseros que en Cali, y en otras ciudades bajo su influencia, se juntan alrededor de un objeto al que se rinde culto.

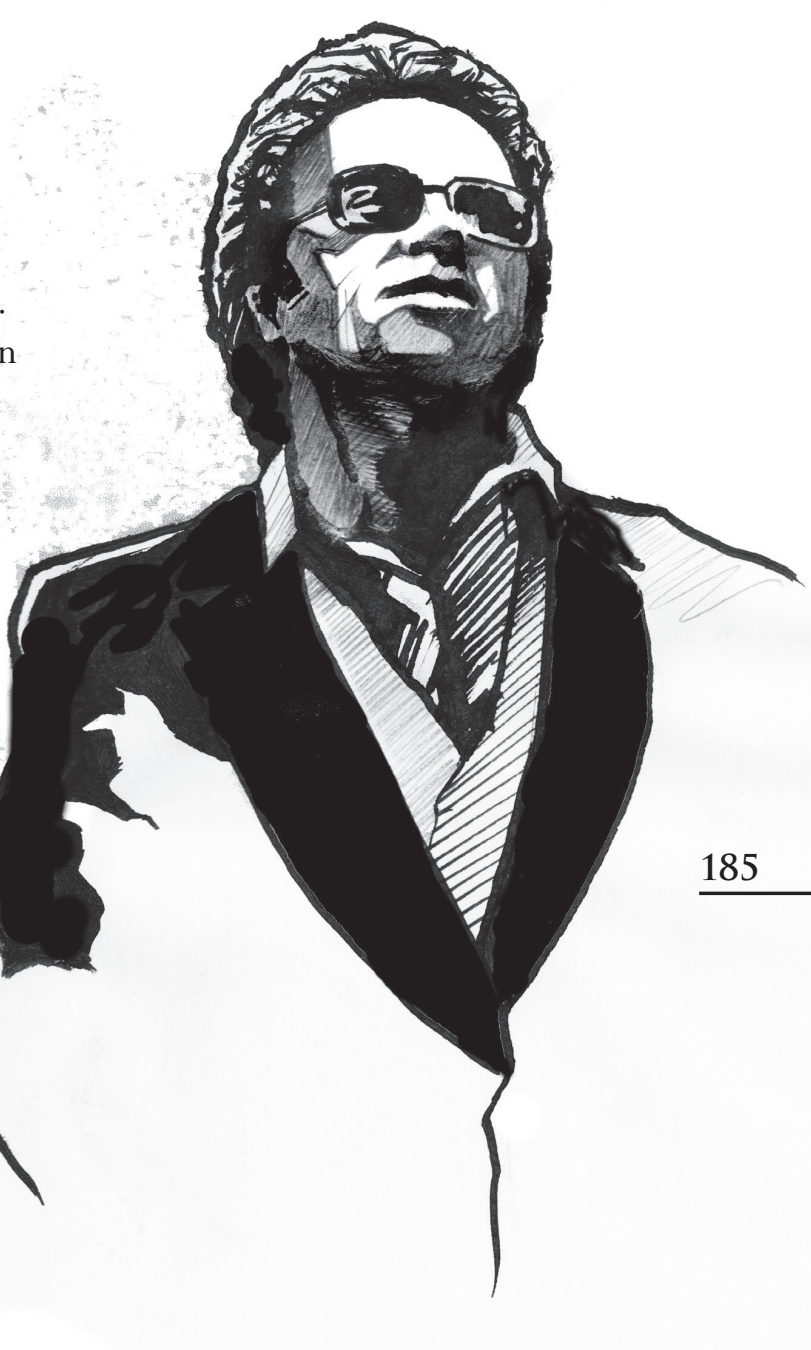

La existencia empírica de una memoria musical ligada a la salsa y la música antillana ("la vieja guardia") es un hecho cultural en Cali, visible en centenas de coleccionistas que soportan esa memoria con un patrimonio en su haber. Miles de discos, conocidos como "La Pasta," conservan viejas canciones que conviven junto al CD y las nuevas tecnologías del sonido. Hay un mercado informal para "La Pasta" en sus diferentes formatos: 78, 45 y 33 revoluciones por minuto (RPM) o en $4 \times 4$ que circulan en audiciones públicas y privadas, en encuentros en los barrios y parques populares, donde los melómanos pueden escucharla, pero también adquirirla mediante la compraventa o el trueque.

Reunirse en torno a "La Pasta" para una audición (que puede incluir el CD) es la mejor forma de resignificar hoy las grabaciones discográficas como una tecnología del sonido que puso en contacto la música afro caribeña con las masas urbanas de América Latina y el Caribe, al promediar el siglo veinte. Entonces, las nacientes ciudades de esta parte del mundo, apenas despertaban a una modernización que marginaba a sus mayorías: mestizos, negros y mulatos, sobreviviendo y luchando por conquistar su lugar en la urbe. Junto al cine y el fútbol, la música grabada en el acetato y difundida a través de la rockola fue en Cali una de las principales formas de recreación y entretenimiento en medio de la violencia política, liberal-conservadora, exacerbada durante los años 50. 
Cali era, a mediados del siglo veinte, una más de las ciudades donde convergían los vientos melodiosos provenientes del Caribe en "La Pasta" y en el cine. Desde entonces, empezaron a preservarse las primeras colecciones de discos en 78 RPM, antes de que apareciera el LP de 33 RPM y "el sencillo" de 45 RPM con los que se consagraría el sonido en estéreo, una maravilla tecnológica que reeducó el oído, después de haber soportado la grabación monofónica, desde comienzos del siglo. En los años 60, el estéreo añadió una nueva sensación a un viejo placer. Las audiciones, donde concurren grupos familiares, amigos y vecinos, o ciudadanos comunes y silvestres de diferentes generaciones, reafirman y recrean ese placer.

La formación progresiva de las colecciones, desde los años 40, intensificada a partir de los 50, es concomitante con la ausencia de la música en vivo, al menos para los sectores populares de Cali. La música que escuchaban a través de la reproducción técnica del sonido, en el acetato, o por medio del cine, compensaba la ausencia física de los grandes ídolos del Star Sistem latinoamericaribeño: desde Carlos Gardel y Libertad la Marque, hasta Toña La Negra, Celia Cruz, La Sonora Matancera, Beny Moré, Rafael Hernández, Pérez Prado y otras figuras de la vieja guardia, algunos de los cuales pasaron por esta ciudad, pero cuya visita fue esporádica. Y con respecto a la vanguardia salsera de los años 60 y 70 en Nueva York y Puerto Rico la situación fue idéntica. Mientras en NY y PR, era común ver a los hermanos Palmieri, Joe Cuba, Tito Puente, Ray Barretto, Rafael Cortijo, El Gran Combo y muchos otros, cuyos discos hacen parte del repertorio compartido en las audiciones, en Cali hubo que esperar varias décadas para apreciarlos.

En otras palabras, a diferencia de lo que pasaba en La Habana, San Juan, Buenos Aires, Nueva York o México, donde permanentemente los músicos actuaban en vivo y en directo, en Cali, brillaban por su ausencia. Su presencia eventual se limitaba a algunas actuaciones en los radioteatros locales o en los teatros de la ciudad, en ambos casos con limitaciones locativas para la asistencia masiva del público, pues sólo podían dar cabida a uno o dos centenares de personas, en los radioteatros, y unos mil asistentes en los teatros, generalmente ubicados en los barrios. ${ }^{4}$ En Cali, sólo las élites podían darse el lujo de tener en sus clubes privados orquestas de importancia nacional e internacional de modo más o menos sistemático, aunque sin la misma frecuencia que en las demás ciudades mencionadas. Y con respecto a las bandas salseras fue sólo a partir de 196869, previo a los Juegos Panamericanos de 1971, durante ellos, y sobre todo después de ellos, con el auge del narcotráfico, que las agrupaciones de salsa vinieron en forma asidua a la ciudad.

Comparada con otras urbes latinoamericanas y caribeñas, la ausencia de la música en vivo durante los años 40 al 60 del siglo pasado en Cali, es una de las razones por las que los discos son el objeto privilegiado de las audiciones, tan importantes como la música misma, porque sin ellos, ésta no es posible, ni es posible el encuentro. Las colecciones discográficas que poseen muchos caleños son uno de los factores que explican el surgimiento inicial, y el auge posterior de las audiciones públicas durante los últimos 25 años. El arsenal de discos disponibles propicia y estimula formas de socialización e intercambio, atravesadas también por otras mediaciones como el gusto por esta música, 
gusto heredado y adquirido, reproducido en el entorno familiar o barrial, asociado con el baile, influenciado por la radio, o iniciado en alguna reconocida salsoteca de la ciudad, como hemos podido constatarlo con el testimonio de diferentes melómanos entrevistados. ${ }^{5}$

Una vez más, citamos a Bourdieu (2000) cuando dice:

En materia de bienes culturales, la producción implica la producción de consumidores, es decir, más concretamente, la producción del gusto por la música, de la necesidad de la música, de la creencia en la música. Para dar cuenta realmente de esto, que es lo esencial, habría que analizar toda la red de relaciones de competencia y de complementariedad, de complicidad en la competencia, que unen al conjunto de agentes implicados, compositores o intérpretes, célebres o desconocidos, productores de discos, críticos, locutores de radio, profesores, etc., en suma, todos los que tienen interés por la música, intereses en la música, inversiones en el sentido económico o psicológico en la música, que están en el juego, atrapados por el juego. (p. 143)

En esta lista de Bourdieu faltó un actor que en nuestro caso es fundamental, o sea el melómano y coleccionista, particularmente el del perfil aquí descrito sobre el que enfatizaremos de aquí en adelante. Porque si bien la producción de bienes implica la producción de consumidores, ello no está totalmente predeterminado. Los usos sociales de los bienes, sus formas de apropiación y las prácticas que se dinamizan en contextos históricos específicos, generan procesos y significados no previstos, como lo sucedido con las audiciones discográficas de salsa y música latina en Santiago de Cali, con base en las colecciones disponibles. Para los coleccionistas, donde es frecuente hallar un disco "raro", exclusivo, o de pequeño tiraje, tener el disco original, antes que una reproducción, es signo de distinción, como lo es poseer principalmente "Pasta americana", es decir, discos grabados y producidos en los Estados Unidos que se caracterizan por una mayor fidelidad en el sonido. En una jerarquización establecida en el medio, le sigue la "Pasta venezolana", y por último, la colombiana, la menos cotizada de todas. De esta categorización se deduce que un buen coleccionista es aquel que no sólo tiene muchos discos, sino, y sobre todo, "pasta americana". Por esta vía, el disco se convirtió en un objeto de culto, una especie de fetiche en torno al cual se congregan sus admiradores. ${ }^{6}$ Muestra de ello es que en el XXIII Encuentro de Melómanos y Coleccionistas que se realiza en Cali durante la Feria, entre el 26 y el 30 de diciembre de 2014, hay un día destinado para una muestra internacional de vinilos y acetatos en 33 y 45 RPM - especial 78, como tributo al caleño Humberto Corredor, considerado tal vez el mayor coleccionista del mundo, fallecido este mismo año en Nueva York, donde vivió durante la segunda mitad de su vida. ${ }^{7}$ 


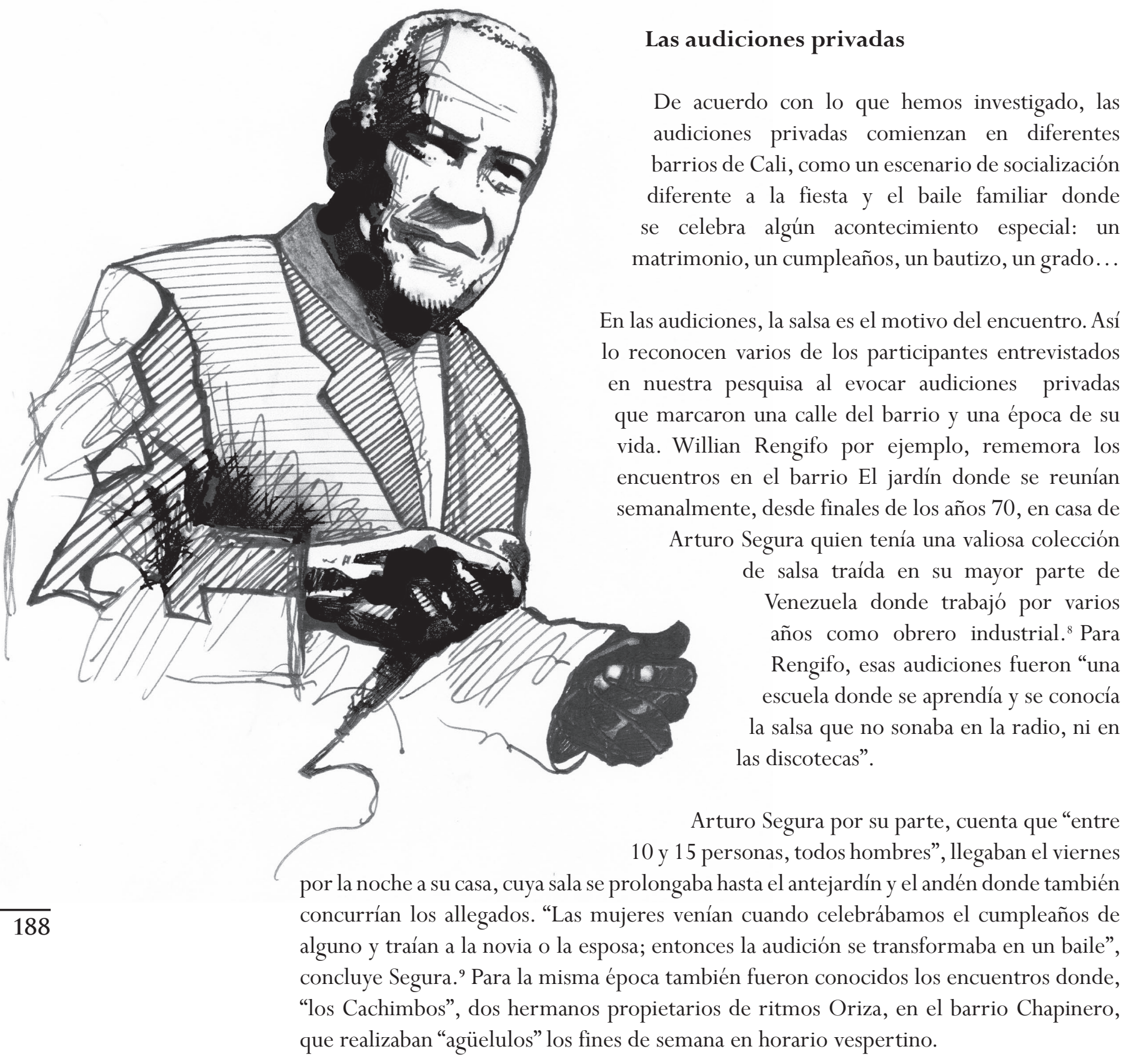

Antes que desaparecer, estas prácticas aumentaron en las décadas siguientes con algunas variaciones, pero conservando el carácter lúdico de un evento donde al mismo tiempo que se escucha la salsa se aprende a conocerla con fruición y placer. El apogeo del narcotráfico en los años 80 y 90 del siglo pasado, consolidó la expansión de la salsa en la ciudad, con la contratación permanente de orquestas internacionales y la creación de bandas locales, con las cuales se incrementó la producción, creció el mercado discográfico y aumentó la industria del entretenimiento, con la aparición de clubes, grilles y discotecas dedicadas a la salsa, principalmente. Al mismo tiempo, las audiciones privadas también se multiplicaron en los barrios, entre empleados de las empresas municipales, trabajadores de varias factorías y colectivos de maestros. 
En 1997 por ejemplo, se iniciaron informalmente las audiciones de los empleados de Propal (una multinacional productora de papel) lideradas por Flavio Antonio Naranjo con otros compañeros que formaron el grupo autodenominado "La Negroteca". Con sus discos rotaban los encuentros por diversos barrios populares de Cali, como Salomia y La Rivera; y por Puerto Tejada, Villarrica y Santander de Quilichao, municipios aledaños a Cali. ${ }^{10}$

En el año 2000 "La Negroteca” se formalizó como una organización de melómanos con el nombre de “Amigos del Son”. Desde entonces, el grupo ha crecido y ha programado más de 150 audiciones hasta la fecha promoviendo la salseridad y conectándose con otros grupos afines como Fuerza Latina, Conciencia Latina y Unimel. Gracias a su nivel organizativo participan con nombre propio en las audiciones públicas en el Parque de la Música y otros escenarios urbanos; así mismo, llevan un registro de sus audiciones en las que cada participante debe documentar la presentación de la música que difunde.

En el año 2008 identificamos nuevas audiciones privadas en el barrio Eduardo Santos, en la casa de los Pedroza, oriundos de Buenaventura. En la casa de Uriel Mancilla en el barrio Villa del lago; también en el barrio El Diamante donde Diego "Salsa", y en la casa de Alonso Alomía, propietario de la antigua Taberna Osos, a donde llegan salseros consumados a compartir lo que cada uno tiene.

Todos los mencionados son barrios populares de Cali, estratos 2 y 3 . El fenómeno también ocurre, sobre todo en la transición al siglo XXI, en pequeños grupos de estratos más altos como en el barrio La Flora - estrato 6 - en la casa de Humberto Cardona "San Timbalio", quien ha organizado un pequeño y lujoso bar con excelente sonido y una amplia colección musical, superior a los 5000 Lps para las audiciones con allegados y amigos. Igualmente las audiciones en casa de Omar Aragón en el barrio Pampalinda, estrato 5, realizadas desde cuando era empleado de las Empresas municipales de Cali. Con un patrimonio de aproximadamente 4000 LPs, Omar Aragón programa audiciones privadas con sus amigos e invitados donde cada uno participa con discos de su colección personal. En época de ferias, Omar Aragón ha organizado verbenas con otros vecinos de la cuadra para escuchar la salsa "a todo timbal".

Como ritual moderno, urbano y profano, en la audición se exhiben y confrontan los prestigios de los coleccionistas, los saberes de los melómanos, los gustos diversos de los salseros, para los que, la calidad del sonido, es un requisito fundamental. 


\section{Las salsotecas}

Aprovechando sus colecciones personales o familiares, algunos melómanos montaron una salsoteca, una especie de bar o taberna en los que se programaba la salsa bajo un concepto diferente al de la discoteca donde se va a bailar. En aquellas, el propósito era básicamente escuchar, apreciar auditivamente la melodía y el ritmo, acompañarlo incluso con una campana, unas maracas o un bongó. Y aunque en un principio tenían sólo ese carácter, parte de la clientela fue imponiendo el baile como una opción no sólo complementaria, sino necesaria a sus deseos, tal como sucedió en la Salsoteca Cachana en la década de 1980, donde mediante una medida extrema se prohibió bailar, pero la joven clientela de entonces terminó rebelándose contra la arbitraria imposición de sus dueños. ${ }^{11}$

El furor de las salsotecas se vivió en los años 80 cuando surgieron más de una docena, varias de ellas en la calle 44, barrio Atanasio Girardot, conocida entonces como "la calle de las salsotecas"en Cali. ${ }^{12} \mathrm{De}$ este modo, las salsotecas, que todavía existen, unas más antiguas que otras, pasaron a ser una variación de las audiciones privadas, pero convertidas en negocio particular.

Entre todas, la más importante fue La Taberna Latina, de Gary Domínguez, por lo que significó para una generación de salseros en la ciudad. Creada en 1982, en el barrio San Fernando (un sector de clase media), La Taberna Latina se tornó poco a poco en una escuela de la salseridad. Allí, Gary Domínguez, gracias a los discos adquiridos por él y el patrimonio discográfico heredado de su padre, realizaba audiciones temáticas especializadas y distribuía una "hoja volante" con la programación de la noche, que incluía una reseña biográfica del artista y su discografía. Para ello se inspiró en varios conversatorios ilustrados sobre jazz, salsa y música cubana, ofrecidos por algunos musicólogos de la ciudad a finales de los 70. Él, por su parte, acompañaba las audiciones con diapositivas, algunos videos en betamax y las hojas sueltas, que dos décadas después se organizaron como un libro titulado El Cuaderno Latino de la Salsa. ${ }^{13}$

Este modelo "pedagógico" de la Taberna Latina se consolidó a lo largo de 20 años, como una propuesta novedosa y atractiva para quienes frecuentábamos dicho establecimiento y fue la base para el surgimiento de las audiciones públicas en la década del 90.

\section{Las audiciones públicas}

Las audiciones públicas se originaron en 1991 con Gary Domínguez, quien se valió de su experiencia en la Taberna Latina y propuso llevar a la calle este tipo de encuentros que se hacían en salsotecas y casas de familia. Con el auspicio de los organizadores de la Feria de Cali convocó a los melómanos y a sus colegas de negocio para dar inicio a esta nueva práctica, la audición pública, que algunos consideraron en aquel momento, como una "cosa rara".

La primera de ellas fue en el parque Panamericano, barrio San Fernando, el 26 de diciembre de ese año, con la participación de 10 salsotecas y la presencia del pianista Larry Harlow, una de las estrellas de la Fania All Stars. Poco a poco los melómanos fueron llegando al parque donde se realizaron las audiciones en la tarde noche a lo largo de la semana. Tiempo después se convirtió en uno de los eventos más apreciados en la Feria de la ciudad. La valoración positiva por parte de melómanos y asistentes, la capacidad de gestión de los líderes y el apoyo oficial que se ganó progresivamente, determinaron su crecimiento y expansión en el transcurso de esa década, y de ahí en adelante. ${ }^{14}$

Desde entonces comenzaron las audiciones públicas de salsa en Santiago de Cali. Sin saberlo, con ellas se inauguraba para sus seguidores una nueva forma de relación con esta música y con la ciudad. Si las audiciones privadas son a puerta cerrada, y se circunscriben al entorno inmediato de la vivienda, 
las públicas se abren a la plaza, el parque y la calle del barrio popular. Es ese, su espacio “natural”. Allí, los salseros se sienten como pez en el agua, en medio de la risa, las bromas y la camaradería, con que suelen vivenciar el encuentro. En ellas no se aceleran los discos, como suelen hacerlo las escuelas de baile para incentivar los pasos rápidos de los bailarines en el show business. Lo que prevalece es la audición de la música como fue grabada originalmente, disfrutada por los salseros junto a la presencia de veteranos bailadores callejeros que aparecen para improvisar y lucir sus mejores pasos.

Luego de la primera experiencia en el parque Panamericano, el evento se trasladó a una zona verde vacía en el norte de Cali que empezó a conocerse como el Parque de la música, en la entrada a Chipichape, donde quedaban los antiguos talleres del ferrocarril del Pacífico. Allí se realizaron dos encuentros sucesivos en época de feria, hasta que en 1994 la administración municipal los prohibió. Los salseros se organizaron y rechazaron la medida reclamando el espacio; la administración cedió, pero decidió cobrar la entrada. Los colectivos se trasladaron con sus seguidores a otros escenarios públicos, denunciaron el hecho y recolectaron unas cinco mil firmas para exigir la devolución del parque, en una pelea que duró varios meses con las implicaciones jurídicas del caso. Una pelea, por lo demás extraña en un país lleno de tantos conflictos, de tantos motines a bordo, de tantas bombas de tiempo. ${ }^{15}$ Mientras se resolvía el litigio, el evento deambuló por las canchas panamericanas, el parque de los poetas y el parque de la retreta, antes de volver al parque de la música donde se estableció por más de una década hasta que fue trasladado a otro lugar.

La asistencia masiva a las audiciones públicas por parte de familias, grupos de amigos y vecinos, así como las formas de esparcimiento colectivo, fomentan una actitud alegre y extrovertida, una espontaneidad en la comunicación y una propensión hacia el diálogo abier to y las relaciones interpersonales. Estas formas de socialización como características antropológicas, configuran un modo de ser proclive a la informalidad en la creación y el fortalecimiento de las relaciones sociales, aclarando que no se trata de una cualidad innata sino de una condición culturalmente procesada por la conjugación de causalidades histórico-sociales y condiciones ambientales que se dinamizan mediante la acción colectiva de grupos determinados.

Así pues, para el caso objeto de descripción, los encuentros permanentes de las audiciones salseras movilizan comunidades de melómanos que interactúan y comparten fraternalmente su patrimonio discográfico, a la vez que disfrutan de la música, el baile y la tarde-noche, mientras promueven otras experiencias en el uso del tiempo libre, construyendo el espacio público que después hará parte de una memoria colectiva, representada en relatos orales, o en fotos y videos, gracias al auge de las nuevas tecnologías. 
Los salseros son los únicos que han dado la pelea por un parque para escuchar la música que desean; el único grupo organizado, entre "las distintas especies de melómanos", en salir a la calle con su música en hombros para encontrarse fraternalmente y compartir esparcimiento y alegría en lugares públicos.

Mediante la apropiación lúdica de estos escenarios, los salseros han dado muestras de coexistencia y solidaridad, generando sentido de pertenencia para con la ciudad y con la música en que se reconocen. Es este el único grupo organizado que se ha tomado un área de la ciudad para hacer de ella un espacio público y mostrar que se puede convivir pacíficamente, alrededor de la salsa, aún en medio de las diferencias más radicales.

Fortalecidos, con la vuelta al "Parque de la Música", los salseros organizados en diversas asociaciones conquistaron un lugar físico y simbólico para reivindicar un gusto y una sensibilidad estético-musical como alternativa frente a la programación convencional de la radio local y la farándula de moda. No es por acaso que se han multiplicado las Asociaciones de Melómanos y Coleccionistas en Cali, y se hayan extendido a otros municipios circunvecinos, así como han proliferado las orquestas y los grupos de baile durante el mismo periodo.

El impacto que produjo esta experiencia de encuentro societal, vivido de manera pacífica y fraterna, generó otras audiciones igualmente en espacios abiertos, sobretodo en calles, plazas y parques de barrios populares como El Obrero, Alameda, Olímpico, Alfonso López, Siete de Agosto, El Diamante, El Poblado, Siloé... o en reconocidas salsotecas de la ciudad (Soneros, La Ponceña, Mulenze, Casa Latina, La Barra de Moe, Palo Mayombe, La Diferente... También en la sede de Acme (Asociación de melómanos y coleccionistas) y algunas en la Universidad del Valle. El uso recreativo del tiempo libre junto a la apropiación de ciertos escenarios para construir espacio público por parte de las comunidades de salseros en Santiago de Cali, fortalece los vínculos entre ellos y propicia relaciones de convivencia gozosa entre los melómanos. ${ }^{16}$

\section{De "Conciencia Latina" a "Nuestra Cosa Latina"}

No es por casualidad que las audiciones en muchos barrios populares de Cali, hayan sido lideradas por nuevas generaciones que asumieron esta bandera con la pasión que tienen las causas verdaderas. En los años 90 del siglo pasado surgieron varios grupos de adultos jóvenes en Cali que se juntaron en torno a la salsa para compartir la música que tienen y disfrutarla de nuevo en los parques y en las casas de los barrios; ellos mismos buscaban los recursos necesarios para montar las audiciones periódicamente. Entre todos, los más consolidados han sido el grupo "Conciencia Latina” del barrio Siete de agosto, Unimel (Asociación nacional de melómanos y coleccionistas, que agrupa a varios colectivos de Cali y otras ciudades), y la Fundación Nuestra Cosa Latina, que durante los últimos tres años ha ejercido un notable liderazgo en la producción de las audiciones en el parque de Santa Librada, conocido actualmente como parque de Jovita. 
Para el análisis me detendré inicialmente en "Conciencia Latina", por su trayectoria y reconocimientos, y luego en Nuestra Cosa Latina. Se trata de jóvenes que en aquel entonces reivindicaban la música salsa por fuera de la radio, por fuera también de las propuestas culturales que se organizan institucionalmente desde arriba por el gobierno de la ciudad. Esto significa un espacio alternativo, ligado a una cierta resistencia cultural; específicamente resistencia contra lo establecido por la moda, por las emisoras y por las discotecas.

En palabras del coordinador de "Conciencia Latina", Oscar Téllez: “...lo hicimos por esa cantidad de música "mala" que nos estaban radiando, y nos metían de manera comercial. En la audición nos damos la oportunidad de divulgar un poco lo que nosotros tenemos o conocemos, y darlo a conocer a las nuevas generaciones o a la gente que no ha tenido la oportunidad de escuchar otras manifestaciones de la salsa." ${ }^{17}$

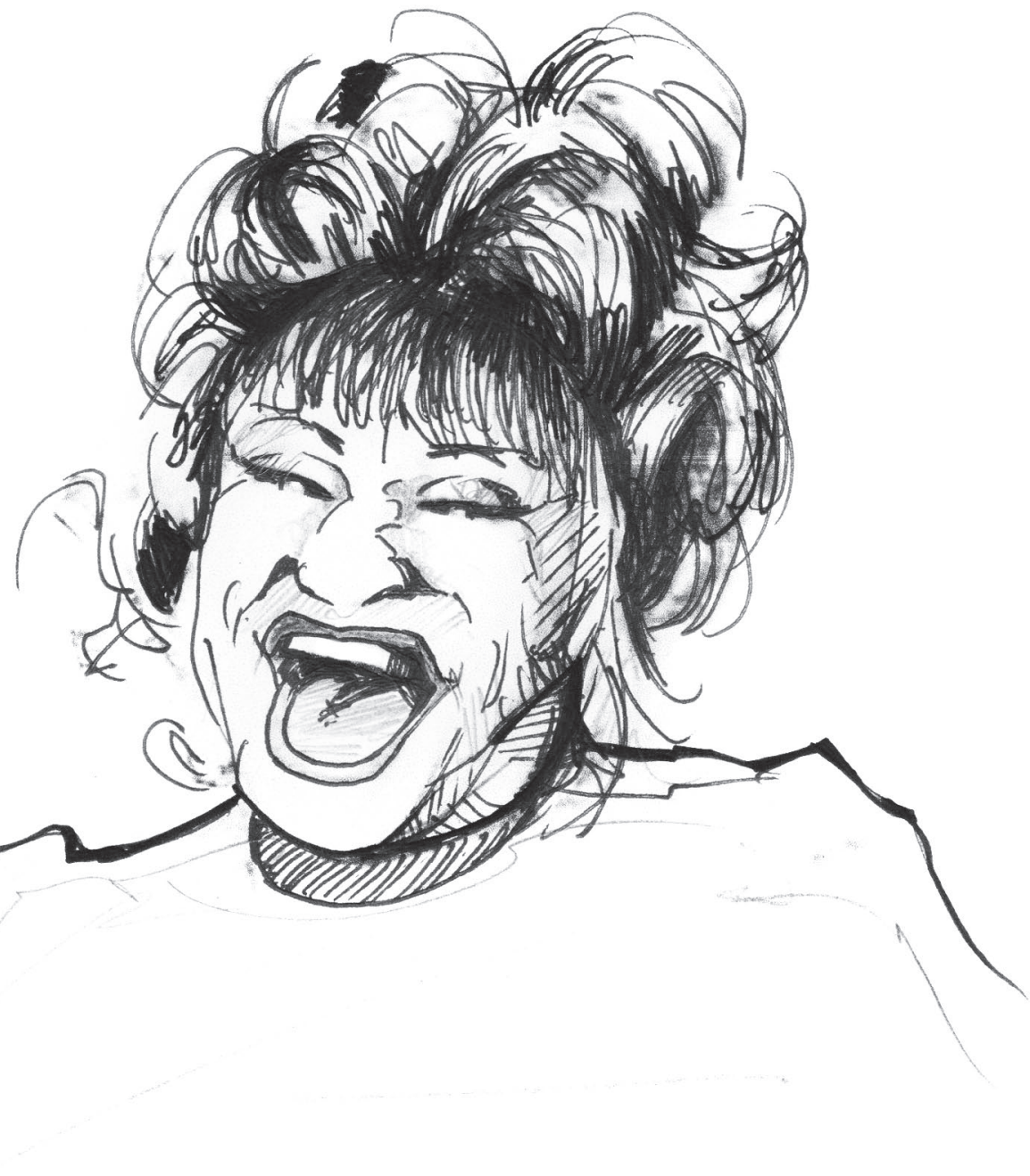


$\mathrm{Al}$ referirse a la realización de las audiciones y la forma de organización del grupo, Oscar Téllez dijo lo siguiente:

Para realizar una audición en un parque se necesitaba apoyo, pero el único apoyo con el que contábamos era el nuestro. La junta de acción comunal del barrio 7 de agosto solo nos daba el permiso, entonces nos reuníamos para definir temáticas y funciones, y la discografía, porque no podíamos llegar el día de la audición a improvisar con la música. Previamente nos distribuíamos la discografía y cada uno llevaba determinados Lps para abordar la mayor cantidad de trabajos posibles de determinado artista. Dentro de las reuniones designábamos funciones; unos se encargaban de la publicidad, hablar con las emisoras; otros llegábamos temprano a desyerbar el parque y tenerlo apto para la audición; unos más esperaban a que llegara la carpa y la cerveza de Bavaria que íbamos a vender; un voluntario se encargaba de instalar el sonido. Iniciábamos más o menos a las 4 de la tarde. Para esa hora debíamos estar todos presentes. Lo básico en este tipo de eventos es que haya un coordinador encargado de registrar el nombre de los invitados, el orden de llegada, y las canciones que proponen para su participación. (Téllez, Cali, julio de 2007)

A pesar de tratarse de una experiencia un tanto marginal y periférica, no solo por su ubicación en la geografía urbana, sino por el lugar que ocupaba con respecto a otras manifestaciones de la cultura salsera en la ciudad, este tipo de audiciones se multiplicaron debido al impacto que tenían en sectores de jóvenes melómanos que decidieron replicarlas en sus barrios, como lo afirma Oscar Téllez:

Gracias a que atraíamos la atención de muchos jóvenes de barrios cercanos, se formaron, por su propia iniciativa 7 u 8 colectivos similares al nuestro, nosotros los apoyamos, el caso más notable es el de Fuerza Latina, que aún subsiste. (Téllez, Cali, julio de 2007).

Un aspecto muy importante en audiciones como las realizadas por ellos, es la relación con el espacio público, pues se busca promover una forma de convivencia pacífica generada en torno a la salsa y su baile, a través de un discurso que ha ganado presencia durante los últimos años. Esta es una experiencia de apropiación de lo público que vale la pena resaltar en la actual situación de nuestro país.

No es casual tampoco que después de tantos años de presencia salsera en la radio, hayan aparecido programas con un concepto diferente al que ha predominado en las emisoras caleñas desde hace cuatro décadas. Varios de estos nuevos programas son realizados por algunos de los melómanos y coleccionistas integrantes o no de los colectivos organizados. 
La salsa nació en el Barrio y desde su origen barrial y callejero estuvo vinculada al espacio público de la cultura popular, a la que pertenece, donde se originó y donde fue desarrollada por sus seguidores. Por eso, cada audición realizada en el Parque de la Música, (hasta el 2010) o en escenarios afines, "es una afirmación de su condición étnica y social a la que nunca ha renunciado, de la que jamás se ha avergonzado”, según dice uno de los asiduos asistentes.

\section{Audiciones, saberes y ritualidades}

Además de clasificarlos por orden alfabético, géneros, temáticas, épocas o por su aparición cronológica, el melómano y el coleccionista enriquecen su patrimonio con información y conocimientos sobre lo que tienen. De este modo, el placer no está sólo en oír la música, sino en asociar la audición a un saber especializado, que aunque no es un saber-cómo (un saber-hacer musical) sino un saber-qué, está investido de un alto valor simbólico que podemos registrar, en términos de Bourdieu, como parte del capital cultural de los actores.

Oír el disco es sacarlo de su cubierta, limpiarlo, bajar la aguja y ponerlo a rodar, configurar el sonido, subir el volumen, modular los bajos, balancear los brillos, afinar el oído para deleitarse con el efecto estereofónico de parlantes o columnas que soportan las cargas de ritmo y energía.

Oír el disco es concentrarse en él y mirar la carátula como si fuera la primera vez, repasar la secuencia de canciones que lo integran, identificar las mejores o las que más gustan, narrar algún episodio al que se liga una canción o simplemente cantarla como si uno fuera el vocalista original.

Oír el disco es entrar en la clave, marcarla con las manos, interpretar el obligado de un bajo, detener el tiempo frente al trueno de un trombón o los riffs de una trompeta, extasiarse con las notas que saltan de un piano como saltan las gotas de lluvia en el asfalto, simular que lo tocan los melómanos y no los músicos, arrebatarse con la descarga de un timbal, el cutuprá del bongó y el kumbakín de las congas.

No hay sonido que no se sienta en su más fina vibración; no hay nota que escape a todos los sentidos; no hay comentario que deje de expresarse en el fragor de una audición, sin detrimento del baile que es parte del goce.

En la ciudad de los afanes, hecha de vías rápidas para fluir y no para estar juntos, la audición pública o privada es un lugar de encuentro para el placer sin prisa. El lugar donde se congregan melómanos y coleccionistas a compartir saberes y placeres. Allí se mezclan la novedad y la repetición, la curiosidad y el deseo, el conocimiento y la pasión que hacen de la cultura salsera un espacio privilegiado para sobrevivir en la ciudad, aún en medio de tanta violencia irracional, de la pobreza extrema y los abusos del poder. 


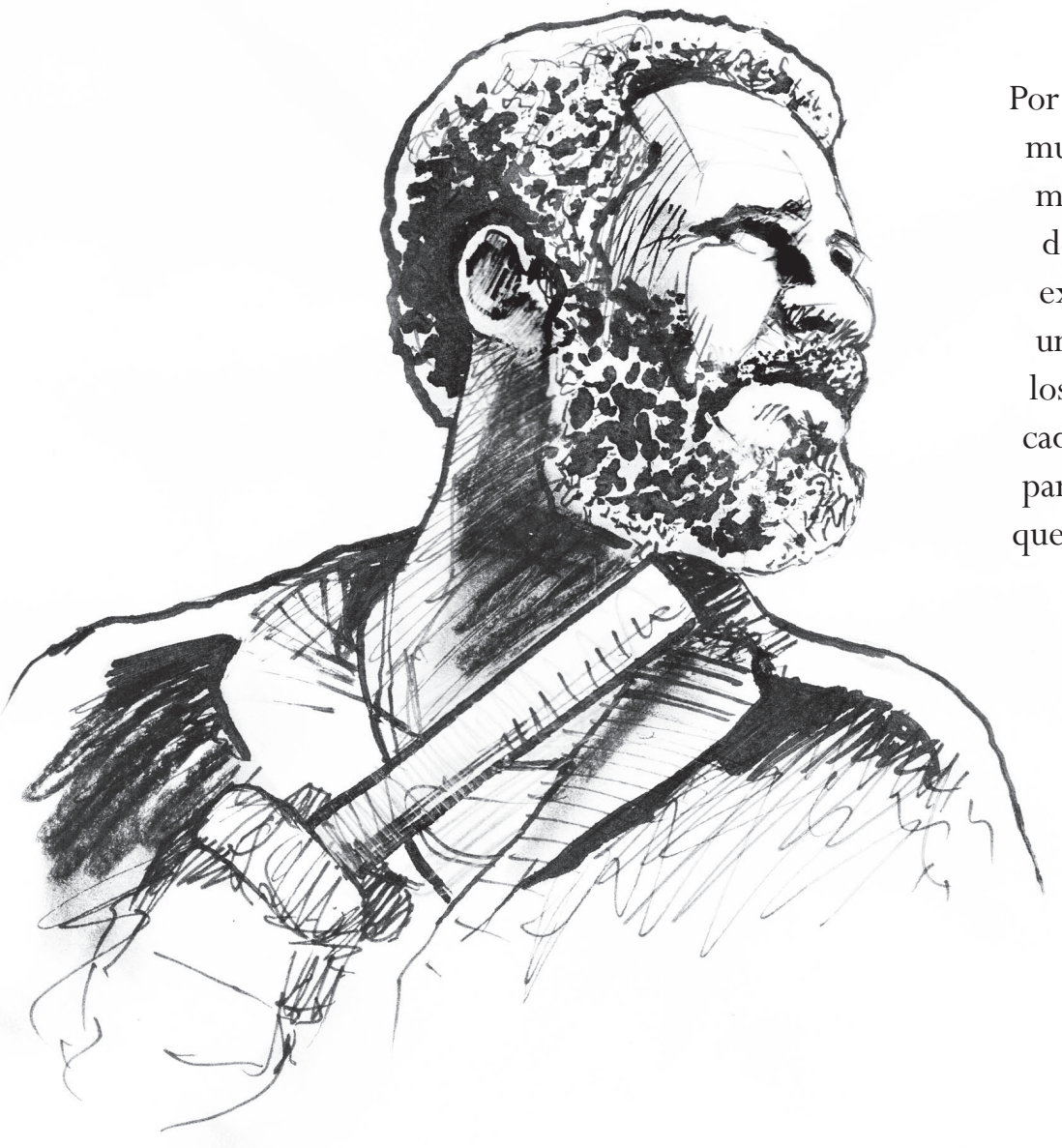

Por lo que significa históricamente para la cultura musical en Cali, las audiciones han ganado un merecido reconocimiento institucional a partir del año 2000. Salseros y Coleccionistas de esta expresión han luchado por ganar y preservar un espacio para el ritual contemporáneo que los convoca y los une. Si continúan vigentes y cada vez con más fuerza, es por lo que significan para comunidades de melómanos y bailadores que se formaron en relación estrecha con la música y el disco en sus distintos formatos.

Porque, así mismo, están ligadas no sólo a la historia de los ritmos afrolatinos, a sus creadores e intérpretes, sino a su comercio formal e informal a través de marineros, discómanos, inmigrantes, proxenetas, prostitutas y taberneros que los dieron a conocer. Eso es lo que también honran las audiciones allí donde se realizan, erigiéndose en espacio alternativo contra las perversiones de la payola y la farándula.

Según varios de los organizadores, en las audiciones ondean las banderas de la mejor salsa, fundada en los toques de la clave, la riqueza polirrítmica, los solos instrumentales, los pregones repentinos, los arreglos desafiantes, la voz de los soneros, las dianas del guaguancó, las descargas y las improvisaciones que se traducen en baile y energía. Una bandera puesta en lo más alto de cada audición salsera - y su baile - que deja huella en el cuerpo de los melómanos y en el cuerpo de la ciudad. Para ellos, esas son las marcas que hicieron de la buena salsa una música revolucionaria para el mundo. Esos son sus ingredientes fundamentales, el sabor y la sazón que la han hecho universal. Las audiciones son el lugar donde ella se despliega a plenitud. Y sobre todo al aire libre, cuando se habita la ciudad de esa manera y donde se construye con música, la ciudad que nos habita interiormente.

Ya sean privadas o públicas, las audiciones surgen como alternativa a las emisoras, la música de moda y las discotecas, para escuchar la salsa que se tiene y se desea; es un escenario para cultivar el gusto, con criterio propio y decisión autónoma, pues se programa por acuerdo entre los participantes, por decisión de quien lidera el evento, o según los parámetros definidos por los colectivos organizados que las llevan a cabo periódicamente, como lo hace el grupo Nuestra Cosa Latina. 
En cierto modo, las audiciones son una forma de resistencia a la hegemonía de la radio, que impone un tipo de salsa mientras ignora otra, según su lógica de rentabilidad comercial, en connivencia con las casas disqueras, e intervenida por la payola, esa "carroña que hiede" en muchos medios de comunicación. ${ }^{18} \mathrm{Si}$ desde los massmedia se establecen gustos, modas y canciones preferidas, las audiciones se erigen contra ellos como una voz disidente que reivindica otro gusto y otro tipo de relación con la música y con la ciudad, al promover una forma de convivencia pacífica generada en torno a la salsa y su baile.

Con respecto a esta diferencia de gustos y propuestas, conviene citar una vez más a Bourdieu cuando afirma:

No hay nada más duro de sufrir que los «malos» gustos de los demás. La intolerancia estética presenta violencias terribles. Los gustos son inseparables de los dis-gustos; la aversión por los estilos de vida diferentes es, sin duda, una de las barreras entre clases más fuertes. $(2000 \text {, p. } 140)^{19}$

Vale aclarar que antes que los antagonismos de clase proyectados en los gustos musicales, según Bourdieu, encontramos otro tipo de antagonismo como es la explícita oposición a la programación radial hegemónica que divulga el último éxito de la temporada, o el "top ten" según sus ratings de sintonía. En esa tensión con el medio de comunicación se construye una forma de memoria que reivindica una música por fuera de la programación radial.

Si por un lado, la audición pública se programa con autonomía, por los grupos que la organizan (Unimel, Nuestra Cosa Latina, Conciencia Latina, Colectivo de profesores y maestros) para compartir, socializar y gozar, por otro también se convierte en un escenario para mostrar lo que se tiene, exhibir un saber que se convierte en poder dentro de los participantes, y ganar reconocimiento entre las comunidades de pares con las que se comparte y se rivaliza fraternalmente.

En ocasiones, la audición incluye un "mano a mano" entre reconocidos coleccionistas de la ciudad, o con invitados de otras ciudades que se dan cita en algún lugar para ello. El carácter agonístico de las audiciones tiene un alto valor simbólico especialmente cuando se programan estos eventos que generan gran expectativa y asistencia, entre los melómanos. Tales enfrentamientos pueden durar horas dado que se realizan entre actores que poseen verdaderos tesoros discográficos, no siempre al alcance de los demás.

Pero, antes que competir, según los mismos participantes, "se trata es de compartir con amigos y conocidos la música que uno tiene", como lo afirma Isidoro Corquidi, ${ }^{20}$ tal vez el más reputado coleccionista de música popular en Cali, junto con Humberto Corredor, recientemente fallecido en la ciudad de Nueva York. 
Aun con esos matices, las audiciones públicas y privadas en torno a la música Latina y la Salsa constituyen un espacio de intensas sociabilidades en Cali, desarrollado durante los últimos 25 años y fortalecido con la presencia de las nuevas generaciones que relevan a los mayores en sus liderazgos y protagonismos.

\section{Las audiciones públicas: dos modelos}

Podemos diferenciar dos modelos de las audiciones públicas. El primero, ya descrito, gestado por Gary Domínguez y centrado en el encuentro de coleccionistas y salsotecas, privilegió la exhibición de las colecciones privadas de quienes aprovechando su patrimonio discográfico, terminaron convirtiéndose en los artistas, por encima de los músicos y de la música misma. Por esa vía, el encuentro de coleccionistas pudo legitimarse como un ritual profano fetichizando un objeto que como "la pasta" se cotizó en el mercado informal, generando formas de intercambio no sólo mercantil sino simbólico, por el prestigio de tener un disco raro, exclusivo, original, o único.

Si bien, el objetivo era compartir la música, socializar y gozar, la audición sirvió también para exhibir un saber que se convierte en poder, y ganar reconocimiento entre las comunidades de pares con las que se comparte y se rivaliza fraternalmente. En algunos casos, el carácter agonístico de las audiciones se ha revestido de una preciada valoración simbólica, especialmente cuando se han programado mano a manos entre dos reconocidos coleccionistas, que se enfrentan ante la audiencia, y que poseen verdaderos tesoros discográficos, no siempre al alcance de los demás. Tales "enfrentamientos" permitieron a muchos melómanos escuchar al menos, canciones jamás oídas, aunque no siempre agradables para todos.

Aún así, con estas audiciones se configuró un nuevo espacio público en Cali: el Parque de la Música, un escenario para el encuentro y el disfrute colectivo y pacífico en torno a la salsa; un escenario que con el tiempo tuvo que abrirse a las presentaciones en vivo de las bandas locales o extranjeras, entre ellas la presentación del maestro Eddie Palmieri y La Perfecta II en diciembre de 2009. En ese año la Corporación de Ferias y espectáculos de Cali - Corfecali- contrató además la orquesta Spanish Harlem de Nueva York; y entre 2010 y 2012 a Willie Rosario, La Sonora Ponceña, La Selecta, Roberto Roena, La Orquesta Mulenze, (las mejores bandas de Puerto Rico); también El Septeto Nacional de Cuba y los Van Van. Como esta tendencia se consolidó en las ferias durante la administración del alcalde Jorge Iván Ospina, (al presentar gratuitamente a todas las mencionadas, y otras), el Encuentro de Melómanos y Coleccionistas empezó a perder la centralidad y el protagonismo adquirido durante 20 años. Para algunos de ellos, "el encuentro se convirtió en una verbena más, donde la gente no va a escuchar los discos sino a ver una orquesta y tirar paso..." Un reconocido coleccionistas agregó: "Se perdió la esencia del encuentro que era escuchar la música que uno no tiene o que ya no se oye, conocer las colecciones de los demás y disfrutarla con los amigos”. ${ }^{21}$ 


\section{Las audiciones públicas: el modelo alternativo}

Gracias a la creciente participación de los melómanos en el Parque de la Música, que surgió y continuó siendo auspiciado por Corfecali con el "apoyo" de la más importante empresa cervecera del país, el modelo de las audiciones públicas se fue expandiendo hasta ser replicado por pequeños grupos de salseros organizados en los barrios del oriente, en el distrito de Aguablanca que empezaron a salir con sus discos a ocupar parques, calles y plazas, de manera sistemática, gestionando con sus propios medios y sin patrocinio oficial alguno, como sí lo ha tenido el Encuentro de Melómanos y Coleccionistas de la Feria de Cali. De todos modos, la apropiación lúdica del tiempo de ocio y el uso recreativo de tales escenarios, fortaleció la creación y expansión de ese nuevo espacio público, en una ciudad donde el espacio público es cada vez menor. ${ }^{22}$

Surgió entonces, paulatinamente, un segundo modelo de audición pública basado en la organización autónoma y la autogestión de diversos colectivos, entre ellos "Conciencia Latina” del barrio Siete de agosto, tal vez el más consolidado en la transición del siglo XX al XXI. Con ellos, hemos podido confirmar el grado de organización y autonomía con que conceptualizan, deciden y programan las audiciones.

Desde la selección temática hasta la distribución de los roles a cumplir, las tareas a ejecutar y la evaluación de cada evento, se evidencia el compromiso con esta causa musical, una especie de militancia salsera, asumida con pasión y sentimiento, pero también con plena conciencia de lo que se hace.

Entre las muchas audiciones públicas, las de mayor importancia para Conciencia Latina y los colectivos organizadores fueron las del barrio Siete de agosto ${ }^{23} \mathrm{y}$ las del Poblado II, porque de allí se desprendieron por lo menos diez audiciones nuevas en otros barrios como El Obrero, Alfonso Bonilla Aragón, El Paraíso y El Rodeo. El colectivo del Poblado fortaleció al grupo de mayor trayectoria que es el del Siete de agosto donde surgieron nuevos liderazgos de jóvenes (Carlos Julio Valverde y Nelson Rengifo, entre otros). Dado que las audiciones se financiaban con la venta de licor, tuvieron su ocaso cuando en el 2007, el gobierno nacional prohibió el consumo de bebidas alcohólicas en espacios públicos. Pero esta ley incentivó los encuentros privados que han continuado realizándose.

De todos modos, las audiciones son un escenario para cultivar el gusto, con criterio propio y decisión autónoma, pues se programa por acuerdo entre los participantes, por decisión de quien lidera el evento, o según los parámetros definidos por los colectivos organizados que las llevan a cabo periódicamente, como lo hacía el grupo Conciencia Latina que realizó 110 audiciones durante 10 años seguidos desde 1997; y como lo hace ahora el Colectivo Nuestra Cosa Latina, en el parque de los estudiantes, antiguo parque de Santa Librada, donde han realizado 40 audiciones temáticas desde el 2010 cuando comenzaron, hasta septiembre de 2014. 
En desacuerdo con el modelo de Gary Domínguez patrocinado por Corfecali, que fetichizó al disco y al coleccionista en detrimento de la música en vivo, los líderes de Nuestra Cosa Latina promueven la coexistencia de ambas modalidades cada vez que pueden. En efecto, han presentado en medio de las audiciones, reconocidas orquestas locales, exponentes de la salsa dura, entre ellas Herencia Salsera, Sounare, Orquesta la Tropa, La Banda Golda y Clandeskina Orquesta. "Para nosotros no hay problema en tener la música en vivo, al contrario, estimulamos y apoyamos las bandas locales que producen buena salsa y quieran compartir tarima en nuestras audiciones", afirma Alex Zuluaga, uno de los líderes del grupo. ${ }^{24}$

Ello hace parte de la programación que proponen en sus reuniones, donde el colectivo discute y aprueba las temáticas de cada audición, se acogen las iniciativas o sugerencias de salseros y coleccionistas amigos o participantes, se realizan diversas formas de gestión y se definen modos de financiación. Con el fin de obtener algún apoyo se han dirigido a diversas entidades públicas y privadas "pero sin éxito alguno". Al respecto, dice Alex Zuluaga:

Al principio, nos financiábamos con nuestros propios recursos y en las audiciones pedíamos un aporte voluntario al público, pero mucha gente no estuvo de acuerdo. Entonces decidimos recopilar canciones seleccionadas de cada audición y grabarlas en un CD que vendemos a los asistentes o a quien los quiera tener; también hemos hecho rifas, además del apoyo del bar La topa tolondra que nos ayuda con los flayers para cada evento. Por otro lado, aunque la Secretaría de Cultura nos ha prometido un apoyo económico, aún no se ha cumplido. (Zuluaga, Cali, agosto 2011)

Otra de las formas de financiación alternativa se da cuando culmina el evento ya que "la rumba" continúa en otro lugar donde se paga un cover de bajo precio, en una fiesta organizada por los mismos integrantes del colectivo, con asistencia de algunos de los participantes en la audición.

El grupo Nuestra Cosa Latina, que empezó con once integrantes y actualmente son nueve, se distribuye las tareas con diferentes roles para cada uno de sus miembros. Dos de ellos manejan el micrófono desde la tarima para la presentación de los participantes y la interlocución con el público; otro se encarga de la logística y el sonido (tarima, luces, equipos); otros dos se encargan de la venta de los Cds y la contabilidad de los ingresos; dos más hacen una especie de curaduría de los discos a presentar. Los curadores a su vez llevan el registro de los participantes y ejercen cierto control o filtro para que las canciones sean acordes con la temática propuesta para cada audición.

Para eso nos reunimos quincenalmente, discutimos las temáticas, y acogemos sugerencias de amigos y conocedores (...) Hasta ahora solo tenemos tres temáticas fijas: una sobre "salsa y boleros", que hacemos en septiembre; otra "salsa pa'l bailador", que programamos en los dos eventos de diciembre; y la última que llamamos "grandes voces", para conocer los mejores cantantes de la salsa. (Zuluaga, Cali, agosto 2011) 
"Inicialmente, la convocatoria

la hacíamos por correo electrónico a partir de una base de datos con 10.000 contactos pero era muy dispendioso", afirma Alex Zuluaga ${ }^{25}$. Actualmente la convocatoria se hace a través de "Radio bemba" y los flayers que se distribuyen principalmente por medio de las redes sociales, para invitar a las audiciones, aprovechando que la fundación Nuestra Cosa Latina tiene su propio sitio web y su página en Facebook. Así mismo circula por las cuentas de Twitter y Facebook de cada uno de los integrantes.

Ahora bien, dentro de los colectivos que han participado de estas prácticas, la nueva tendencia se separó del concepto predominante hasta el 2010, que excluía la música en vivo. Por eso, las audiciones de Nuestra Cosa Latina difieren de las realizadas por Corfecali, (donde el disco y el coleccionista siguen siendo prioritarios) al darle cabida a la música en vivo y al baile como expresiones de esa cultura configurada en sectores populares y de clase media en Cali, que aquí llamamos la cultura salsera, o la Salseridad. De todos modos, vale la pena resaltar esta experiencia de apropiación de lo público, en condiciones de fraternidad y convivencia, en una ciudad sitiada por violencias de todos los colores. Otra de las diferencias frente al evento oficial de Corfecali es que Nuestra Cosa Latina estableció una periodicidad regular que ha mantenido, con las audiciones el primer sábado de cada mes, entre las 4:00 pm y las 12:00 am, mientras Corfecali sólo realiza dos eventos en el año, el Festival de Salsa y Verano en julio-agosto, y el Encuentro de Melómanos y Coleccionistas, del 26 al 30 de diciembre.
Los eventos de Nuestra Cosa Latina se realizan en el parque del colegio Santa Librada (remodelado varias veces por la modernización urbana), junto al monumento de Jovita Feijoo, una mujer que se convirtió en personaje típico de los años 60 en Cali. Se trata de un espacio abierto a la orilla de una vía arteria con facilidades de transporte, por donde circulan también muchos peatones de los barrios aledaños (Alameda, San Bosco, San Cayetano, El Peñón, San Antonio, la Loma de la Cruz, San Fernando y Miraflores). ${ }^{26}$

La observación sistemática nos permite afirmar que durante las audiciones se pueden identificar cuatro escenarios donde se localizan los asistentes: 1. La tarima con los micrófonos y los equipos para la presentación de los discos por los participantes, acompañados por los miembros del colectivo. También es usado para las orquestas en vivo. 2. Un espacio central que rodea el monumento de Jovita, donde se reúnen los asistentes, muchos de los cuales deciden bailar espontáneamente, como solistas o por parejas. 3. Pequeñas graderías, generalmente llenas por la facilidad para sentarse frente a la tarima. En estos tres escenarios es donde se concentran los salseros "duros", que se distinguen no solo por el baile sino porque conocen la música, la cantan y portan, muchos de ellos, algún instrumento de percusión, generalmente campanas, güiros y maracas. Es significativa la presencia de las mujeres salseras que tocan alguno de estos instrumentos. 4. En la parte posterior, una zona verde donde se ubica un público más variado (artesanos, neohippies, 
rockeros, salseros que van y vienen) en un área de la que fluye un verde y cálido aroma que se esparce por todo el parque y estimula sensaciones y percepciones imprevistas para algunos. Hay un área adicional sobre el puente de la vía artería (calle 5, dirección norte sur) en el que mucha gente estaciona sus vehículos para observar panorámicamente y desde arriba un encuentro en el que la salsa y sus ritmos se toman la calle.

Según Alex Zuluaga, a Nuestra Cosa Latina le interesa fortalecer la cultura salsera y por eso incluyen "el baile y están abiertos al surgimiento de las nuevas orquestas locales", aunque las audiciones enfatizan en mantener o recuperar el sonido salsero de los $70^{\prime} \mathrm{s}$, de Nueva York y Puerto Rico.

Por otro lado, el colectivo Nuestra Cosa Latina ha integrado a los blogueros y los Djs que tienen un lugar protagónico en el espacio virtual, algo que también hace parte de las audiciones de Corfecali. En vez de los mano a mano convencionales sólo entre coleccionistas, han propuesto los intercambios musicales bien sea entre salsotecas, Djs, directores de programas, blogueros y melómanos en general, porque la audición, para este colectivo,

Es un espacio para conocedores y no conocedores...Y aunque los coleccionistas dinamizan el evento, no es exclusivo para ellos. Hemos hecho una ruptura con respecto a las audiciones de los 90's, que se concebían como eventos de coleccionistas para coleccionistas, por eso hablamos de encuentro de salsómanos y no de coleccionistas (...) Ahora mismo tenemos un desacuerdo con los organizadores de la Feria que están hablando de la "esencia" de las audiciones, y no hablan de la música, sino del lugar central del coleccionista, porque se creen más artistas que los músicos. Por esta razón, nos distanciamos este año (2012) del encuentro de coleccionistas y melómanos de la Feria de Cali. (Zuluaga, Cali, agosto 2011)

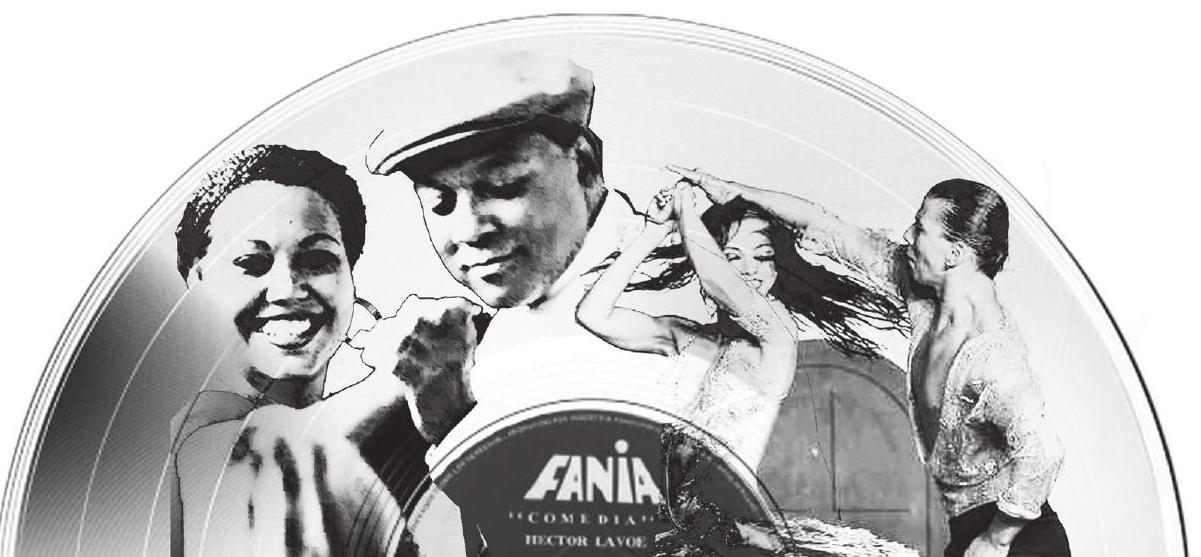


Ahora bien, en estas audiciones no encontramos una ruptura generacional como la que sí percibimos en el gusto por la salsa choke y su baile, que también es diferente al baile tradicional de la salsa en Cali. En las audiciones reseñadas lo que hallamos es una continuidad con la mejor tradición salsera de los barrios populares donde se afincó la "salsa dura" desde los años 60, y dio origen a una memoria musical que se fortalece y se revitaliza con las diferentes clases de encuentros entre melómanos y coleccionistas, de las que participan no sólo adultos, sino también otros jóvenes, hombres y mujeres que gozan con la salsa.

La capacidad de convocatoria de Nuestra Cosa Latina les ha permitido llenar un área relativamente pequeña con capacidad para unas 1000 personas, pero al que asisten hasta 5000, como sucedió en la últimas audiciones que presenciamos, realizadas el sábado 2 de agosto, el 6 de septiembre, el 4 de octubre y el 1 de noviembre 2014.

Comparadas con el evento de Corfecali, celebrado 15 días antes de la de agosto, las audiciones de Nuestra Cosa Latina son mucho más intensas, a pesar de no contar con toda la infraestructura, la logística y el espacio físico que sí tienen los eventos de Corfecali, producidos en las Canchas Panamericanas, al aire libre, con capacidad hasta para 20.000 personas, dotado de pantalla gigante, luces, tecnología digital, presencia de algunas emisoras locales y del canal regional Telepacífico. Con todo, la asistencia a este evento no pasó de unas 1000 a 2000 personas por día, a pesar de las excelentes condiciones climáticas y la promoción que se hizo.

Aunque la comparación es válida por la cercanía de los dos eventos a los que asistí, y el ser ambos audiciones de salsa, no puede generalizarse, ni extenderse a otros casos como las audiciones del fin de año en la feria de Cali, cuando los resultados han sido otros. De todos modos, alguna diferencia hay de por medio y merece un análisis más complejo que no asumiremos aquí.
Pero más allá de las diferencias entre ambos, o entre los discursos de sus organizadores, se ha configurado un espacio público que se consolida con cada nueva audición salsera, mediante la apropiación colectiva y ruidosa del espacio, no por parte de la muchedumbre anónima, sino "en manos de" grupos y comunidades que se encuentran cara a cara para la fiesta, en la celebración del mundo. La calle, aun con todos los peligros derivados de las pandillas y la inseguridad, es el lugar para la algarabía y la extroversión, sobre todo para quienes viven una intensa relación con la música y el baile. Y como las audiciones son una de las formas de apropiación de la salsa, coexisten con otras prácticas en el contexto urbano como la verbena callejera, el concierto privado y otras formas de encuentro.

Ahora bien, retomando a Bourdie en otra de sus declaraciones, encontramos en las prácticas descritas una experiencia social que impugnaría uno de sus puntos de vista cuando dice:

Las dos maneras de adquirir la cultura musical están asociadas a dos modos de consumo de la música: por una parte, la familiaridad originaria con la música; por la otra, el gusto pasivo y académico del aficionado de vinilos. Dos relaciones con la música que se piensan espontáneamente la una en relación a la otra. (Bourdieu, 2000, p. 142)

De acuerdo con nuestro análisis sobre el objeto propuesto puede concluirse que contrario a lo que afirma Bourdieu, no se trata del "gusto pasivo y académico del aficionado de vinilos”, sino de una práctica social colectiva, que moviliza voluntades y deseos; que activa formas de gestión y organización también colectiva y además autónomas, de las que participan comunidades de melómanos urbanos, con un discurso favorable a la construcción de lo público y con connotaciones políticas específicas. 
Agreguemos que en las formas de consumo descritas, a través de las audiciones públicas y privadas, a lo largo de cuatro décadas, se evidencia un proceso cultural donde se resignifican los bienes culturales como esperamos haberlo demostrado en este artículo.

Por otro lado, en esa relación vital con los espacios públicos y en la articulación de las prácticas descritas se configura una "estructura de sentimiento" (expresión del historiador Raymond Williams), es decir un sentimiento pensado y un pensamiento sentido por medio del cual se expresa la relación con el otro y la relación con la ciudad, de una manera afectuosa, con una actitud positiva hacia ellos, aún en medio de los conflictos urbanos.

Es en el tiempo de ocio y en el espacio público construido donde se intercambian los lenguajes y se celebran las prácticas que hacen menos dura la supervivencia. Esta relación con el espacio es una de las características de la cultura popular caleña, cuyos agentes sociales tienden a ocuparlo colectivamente, mientras las élites burguesas suelen recluirse en la privacidad de sus cómodas viviendas, (casas, fincas, apartamentos u oficinas). Pero los sectores populares «invaden» (y configuran) el espacio público de una manera extrovertida, escandalosa, cuando se trata de la fiesta, el carnaval o la protesta, o incluso en las labores de supervivencia cuando pregona sus servicios o vende desde la calle sus productos. ${ }^{27}$

Estas formas de apropiación de la calle son diferentes de las movilizaciones políticas que confrontan el régimen como ha sucedido en los últimos años en Colombia con la movilización de los estudiantes universitarios contra la privatización de la educación y la reforma de la ley 30 en el año 2011; el paro cafetero y el paro agrario de 2012; la movilización de los médicos y estudiantes de medicina por mejores condiciones para la salud pública en el 2013; y las permanentes movilizaciones de los indígenas en defensa de su territorio y su cultura.

De todas maneras, las formas de apropiación mencionadas corresponden a lo que Henry Lefebvre llama "las prácticas espaciales", como también son las audiciones con la diferencia de que estas últimas, son más regulares, sistemáticas y menos coyunturales. Pero también porque están asociadas al tiempo de ocio y los usos del espacio sin que haya siempre una intención política explícita (como sí lo hay en la protesta), pero que terminan convirtiéndose en actos políticos en tanto ejercicios de construcción de una ciudadanía cultural que reivindica un gusto musical y se afirma en él.Y como la estética no se reduce al ámbito de las artes, es posible concluir que en las audiciones públicas en tanto escenario de emociones y sentimientos compartidos, se enriquece la experiencia social de los participantes, sabiendo que son uno, entre otros muchos actores que procuran legitimidad y reconocimiento, a través de iniciativas de producción y consumo de expresiones artísticas y culturales en el espacio urbano. 
Por lo anteriormente expuesto hay suficientes evidencias para concluir que las audiciones hacen parte en Cali, de los usos sociales de la salsa, de otras formas de apropiación, y que en unos y otras se han construido sociabilidades, establecidas ya como instancias fundamentales de una cultura popular urbana y contemporánea. A través de las audiciones, cada vez más presentes en la vida citadina, se ha construido un nuevo tipo de espacio público, como un lugar de convivencia colectiva, lo cual es de suma importancia en una ciudad signada por la violencia.

Ese espacio público, configurado a partir de las sociabilidades festivas que le dan vida, coexiste junto a otros en un complejo que hace parte de la cultura salsera, con las tensiones propias de las relaciones sociales, en un campo cada vez más disputado como ha llegado a ser el fenómeno de la salsa en Cali en lo que va del siglo XXI.

\section{Notas}

${ }^{1}$ En una entrevista al sociólogo francés Pierre Bourdieu, titulada El origen y la evolución de las especies de melómanos, (2000), él se refiere a los gustos musicales y su adscripción a determinadas clases sociales, resaltando las audiciones de la música "culta", cuando afirma: "Basta con (...) evocar las poses y las posturas concentradas y recogidas que los oyentes se sienten obligados a adoptar en las audiciones públicas de música" (Bourdieu, 2000, p. 139). Como veremos, las audiciones salseras se caracterizan justamente por todo lo contrario: la extroversión, la algarabía, el movimiento, el baile y "el corrinche" en el que el cuerpo ocupa un lugar central. La performatividad corporal en el espacio abierto de calles, parques y plazas es uno de los rasgos que definen las audiciones salseras como un lugar de encuentro y comunicación.

${ }^{2}$ Sabemos de estudios como los de Micael Herschmann realizados sobre prácticas de recepción y consumo musical a través de conciertos presentados por agrupaciones brasileras en espacios públicos de Río de Janeiro o en áreas destinadas al espectáculo y el entretenimiento, prácticas que él denomina “territorialidades sónico -musicales”. Ver: Herschmann, M. Lapa, cidade da música. Desafios e perspectivas para o crescimento do Rio de Janeiro e da indústria da música independente nacional. 2007. Del mismo autor: Potencial movente do entretenimento, da música e espacialidade no Rio de Janeiro 2012. También, Territorialidades Sônicas e resignificação de espaços do Rio de Janeiro 2011. En ellos se alude a la música en vivo y no a las audiciones discográficas en espacios públicos.

${ }^{3}$ De acuerdo con el arquitecto y urbanista Carlos Botero, "La ley 388 de 1997 desarrolla el concepto, el mismo que se complementa con el decreto1504 del 4 de agosto de 1998, 'por el cual se reglamenta el manejo del espacio público en los planes de ordenamiento territorial'”. Carlos Botero: "Plaza, parque y zona verde en el desarrollo urbano de Cali en el siglo XX”. Informe final de investigación. Escuela de arquitectura Universidad del Valle, Cali 2004.

${ }^{4}$ De la asistencia masiva en las casetas de baile programadas para la Feria de Cali con capacidad para 5.000 a 10.000 espectadores en las décadas del 60 y 70, se pasó al espectáculo multitudinario en los festivales de orquestas de salsa realizados en el estadio olímpico Pascual Guerrero que albergaba hasta 30.000 o más espectadores, durante la década del 80 .

${ }^{5}$ Entre ellos, Johnny Santacruz, Andrés "Pachanga" y Diego Echeverry, adultos jóvenes y reconocidos salseros de la ciudad cuando integraban el Grupo de Investigación Palo de Mango - Culturas Musicales Urbanas de la Diáspora Afrolatina. Universidad del Valle, Cali 2010. Otros melómanos - coleccionistas heredaron de su padre una amplia colección discográfica de los años 40 y 50 que incluía tangos además de música latina. Por razones comerciales, o por gusto, al pertenecer a la generación de salseros de los años 70, continuaron con el coleccionismo una vez que tuvieron el poder adquisitivo para hacerlo. 
En la hipermedia salsa barrio cultura pueden verse varios videos documentales sobre coleccionistas caleños como Antonio Salcedo, Humberto Corredor, Gary Domínguez y Carlos Adams, entre otros. Este último, oriundo de Buenaventura y trabajador de Colpuertos, era uno de los que tenía acceso a los barcos de la Flota Mercante Gran colombiana cuyos marineros traían cajas llenas de discos provenientes de Nueva York, Puerto Rico o Panamá, para vender en la zona de tolerancia del puerto, o a taberneros, discómanos y dueños de bares y discotecas en Cali, que viajaban hasta Buenaventura para comprarlos.

${ }^{6}$ Un Lp puede llegar a tener un alto valor económico en el mercado informal de "La Pasta", pues se pagan hasta 500 dólares o más por un disco deseado. A un reconocido coleccionista local (cuyo nombre nos pidió mantenerlo en reserva) le cobraban 1.500 dólares por “Mi china me botó" el primer disco grabado por Héctor Lavoe. Lo grabó con La New Yorker, en 45 RPM, a mediados de los años 60. Este single - o sencillo - se ha convertido es una verdadera pieza de lujo para los interesados.

${ }^{7}$ Sólo en ese día participan 22 coleccionistas, incluidos tres de Bogotá, dos de Medellín, uno de Buga, uno de Tuluá, uno de San Andrés, uno de Miami y uno de Europa. Los doce restantes son de Cali.

${ }^{8}$ William Rengifo: entrevista con el autor. Cali, junio de 2005.

${ }^{9}$ Arturo Segura: entrevista con el autor. Cali, abril de 1985. Ver también el documental Cali Pura Salsa, en la serie Un Día en la vida de...RTVC Señal Colombia 1986. Este documental puede verse en la hipermedia http://salsabarriocultura.univalle.edu.co. (2014) - Grupo de Investigación Palo de Mango, Escuela de Comunicación Social - Universidad del Valle, Cali.

${ }^{10}$ Información suministrada por Flavio A. Naranjo en entrevista con el autor. Cali, agosto de 2010

${ }^{11}$ Ver hipermedia salsabarriocultura: http: / / salsabarriocultura.univalle.edu.co.

${ }^{12}$ Recordamos entre otras: La Clave, La Mulenze, La Cuna del Son y La Ponceña, que aún existe en el mismo lugar, desde hace 30 años.

${ }^{13}$ D. J. Gary Domínguez: El Cuaderno Latino de la Salsa - 100 Biodiscografías Salseras de la Taberna Latina. Cali Colombia. Ediciones Salsa Latina, Cali Colombia. Primera edición 2005 New York / Colombia

${ }^{14}$ En el Encuentro de Melómanos y Coleccionistas de 2014 en Cali participan una docena de bares y discotecas de "Música Antillana” (vieja guardia de Cuba, Nueva York y Puerto Rico); 10 salsotecas, 24 asociaciones de coleccionistas agrupadas en la Unión Naciuonal de Melómanos y Coleccionistas (UNIMEL) una docena de coleccionistas particulares, incluidos uno de Bogotá, uno de Medellín, uno de Cuba, uno de Nueva York y otro de México.

${ }^{15}$ Parte de esa historia quedó registrada en el documental "Había una vez... un parque de la música", Escuela de Comunicación Social - Universidad del Valle, Cali, 1994. Puede verse también en http:// salsabarriocultura.univalle.edu.co

${ }^{16}$ Aunque las audiciones surgen como un encuentro entre hombres y son un evento mayoritariamente masculino, en la década del 80 del siglo pasado empiezan a participar unas pocas mujeres, incluso como discómanas, entre ellas Claudia Parra, María Claudia Giraldo, Estela Domínguez y Adriana Orejuela. En el XXIII Encuentro de 2014, el 30 de diciembre está destinado a "La mujer Latina" y participan unas 25 mujeres, incluidas una de Cuba, una de Miami, y los colectivos: Asociación Mujer Sonora y el Club Damas de la Salsa.

${ }^{17}$ Oscar Téllez, coordinador del grupo Conciencia Latina, entrevista con el autor. Cali, julio de 2007

${ }^{18}$ La expresión es de César Miguel Rondón, escrita en El Libro de la Salsa - Crónica del Caribe urbano (1980). Un reconocido músico nos contaba que al lanzar su producción en un CD recientemente, lo presentó a un reconocido programador musical de una emisora en Bogotá, quien le pidió 30 millones de pesos por radiar su música. Esa es la payola.

${ }^{19}$ En relación con los gustos musicales, la exclusión de los gustos es multidireccional. Parece ser la tendencia predominante, antes que la aceptación y los encuentros entre las diferencias. Casi que todos tienden a excluirse mutuamente, aunque cada uno tenga su propio espacio, y aunque haya eventuales convergencias entre géneros musicales y sus respectivas estéticas en la ciudad. Las jerarquizaciones, las valoraciones y la tolerancia o no de los demás gustos y expresiones musicales hacen parte de las tensiones propias del campo musical contemporáneo. Un ejemplo de ello está en el rechazo que los salseros "duros" manifiestan contra la salsa choke, o contra el reguetón, en Cali, a los que consideran como música comercial de poco valor, sin contenido ni calidad que valga la pena. A partir de esa valoración la salsa choke no tiene cabida en las audiciones salseras. En ese contexto resulta pertinente la afirmación de Ranciere según la cual cuando rechazamos contar 
con alguien como perteneciente a la comunidad política, (cultural diríamos aquí) "lo que rechazamos inicialmente es oirlo como sujeto hablante. Oimos sólo el ruido, no lo que él dice...”. Lo que los jóvenes expresan con la salsa choke es la diferencia frente a la salsa de los mayores, y aunque les gusta y tienen una conexión con ella, quieren establecer su propia voz, auspiciados por una pequeña industria y un mercado local que ha ganado presencia mediática durante los últimos cinco años.

${ }^{20}$ Isidoro Corquidi, entrevista con el autor. Cali, julio de 2010. Su amplio apartamento en la ciudad, donde suele reunirse con unos cuantos amigos, alberga aproximadamente unos 15.000 Lps.

${ }^{21}$ Frases recogidas por el autor en las discusiones suscitadas en torno a la preparación del Encuentro de Melómanos y Coleccionistas del 2009 y 2010, donde participó activamente como uno de los organizadores.

Algunos críticos cuestionaron posteriormente la gratuidad que asumió la alcaldía de Jorge Iván Ospina y Corfecali, "porque la gente se acostumbró a ver las mejores orquestas de salsa gratis y después no querían pagar por ningún artista nacional o extranjero”, según lo manifestaron públicamente.

${ }^{22}$ La progresiva expansión urbana y el trazado de nuevas vías principales y secundarias, ha reducido notablemente los espacios para la recreación y el ocio que en tiempos pasados eran potreros, canchas de fútbol y amplias zonas verdes a la orilla de los ríos que bañaban la ciudad. Al respecto, ver A. Ulloa: La Salsa en Cali, especialmente los capítulos 10 y 11 .

${ }^{23}$ Parte de esa experiencia quedó registrada en el documental “Conciencia a golpe de clave”. Escuela de comunicación social, Universidad del Valle, Cali 1997.

${ }^{24}$ Alex Zuluaga, entrevista con el autor. Cali, agosto 2011. Lo sucedido durante la administración del alcalde Ospina y la amplia aceptación de muchos melómanos para apreciar la música en vivo, ha generado cierta forma de presión a las posteriores audiciones de Corfecali que han terminado presentando algún concierto como cierre del evento. Así sucedió por ejemplo en el Festival de Salsa y Verano realizado en julio 18 -20 de 2014, que terminó con el concierto de "El Nene Lugo", cantante cubano, acompañado por el septeto Son Varadero de Cali. En dicho evento hubo un día para la presentación de varias agrupaciones locales de salsa, entre ellas Julio Cortés y su Corte, la Big Band del Pollo Burbano, La Misma Gente, Toño Barrio, Clandeskina, Proyecto Calibre, Sounare, y otra vez "El Nene Lugo.”

${ }^{25}$ Alex Zuluaga, entrevista con el autor. Cali, julio de 2014.

${ }^{26}$ El uso de este lugar se da en el contexto de intervención y altas inversiones oficiales en los espacios urbanos, sobre todo para la movilidad y el transporte, como los impulsados por las Megaobras a partir del 2010 que han generado el Boulevard del río, la plazoleta Jairo Varela, además de otros espacios abiertos en el oriente de la ciudad.

${ }^{27}$ Bien sabemos la importancia del pregón callejero en la inspiración de muchos compositores en Cuba, Puerto Rico, Nueva York y Cali, que le han cantado no sólo al barrio y la calle, sino al vendedor que grita melodiosamente anunciando lo suyo. («El manisero» de Moisés Simons, «Frutas del caney» de Feliz B. Cainet, «El Piraguero» del Conjunto Clásico, «El Patillero», Fruko y sus tesos; «Cuajada» de Bruno Díaz). La algarabía, la risa y «el vacilón» constituyen comportamientos habituales de los sectores populares en su ruidosa ocupación del espacio público en las ciudades.

\section{Referencias}

Botero, C. (2004). Plaza, parque y zona verde en el desarrollo urbano de Cali en el siglo XX. Informe final de investigación. Escuela de arquitectura. Cali: Universidad del Valle.

Bourdieu, P. (2000). El origen y la evolución de las especies de melómanos. En Cuestiones de sociología. Madrid: Istmo.

Domínguez, G. (2005). El Cuaderno Latino de la Salsa - 100 Biodiscografías Salseras de la Taberna Latina. New York: Ediciones Salsa Latina.

Herschmann, M. (2007). Lapa, cidade da música. Desafíos e perspectivas para o crescimento do Rio de Janeiro e da indústria da música independente nacional. Rio de Janeiro: Mauad X.

(2012). Potencial movente do entretenimento, da música e espacialidade no Rio de Janeiro en: Entretenimento, Felicidade e Memória - forças moventes do contemporâneo. 1. São Paulo: Anadarco. (2011). Territorialidades Sônicas e resignificação de espaços do Rio de Janeiro. Rio de Janeiro: Logos (UERJ. Impresso) 
Lefebvre, H. (1968). El Derecho a la Ciudad. Paris: Le droit à la ville.

Rondón, C. (1980). El Libro de la Salsa - Crónica del Caribe urbano. Caracas

Ulloa, A. (1992). La salsa en Cali. Cali: Centro editorial Universidad del Valle.

\section{Videografía- Recursos Electrónicos}

RTVC Señal Colombia. (1986). Cali Pura Salsa, en la serie documental Un Día en la vida de... Escuela de comunicación social. (1997). Conciencia a golpe de clave. Cali. Universidad del Valle. Escuela de Comunicación Social. (1994). Había una vez... un parque de la música. Cali.

Universidad del Valle.

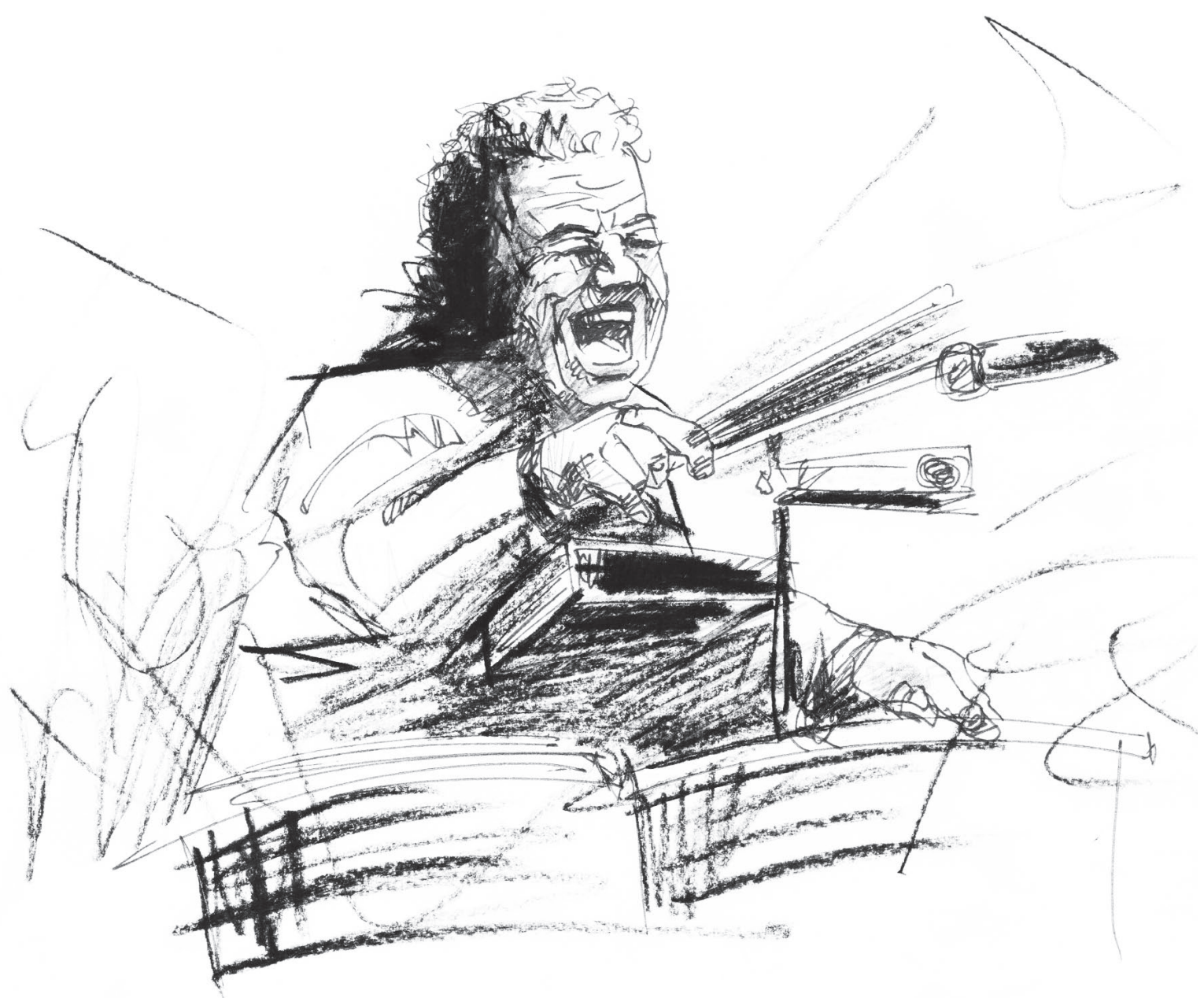

